\title{
5-Formylcytosin ist vermutlich eine semi-permanente Base an definierten Genompositionen
}

\author{
Meng Su, Angie Kirchner, Samuele Stazzoni, Markus Müller, Mirko Wagner, Arne Schröder und \\ Thomas Carel${ }^{*[a]}$
}

"Center for Integrated Protein Science am Department Chemie der Ludwig-Maximilians-Universität München, Butenandtstrasse 5-13, 81377 München. [a] Korrespondenz an Thomas Carell, thomas.carell@Imu.de http://www.carellgroup.de

Veröffentlicht am 19.09.2016 in Angewandte Chemie, 128(39), 11974 - 11978

\begin{abstract}
Die epigenetische Base 5-Formyl-2'-desoxycytosin (fdC) wurde kürzlich im Genom von Stammzellen entdeckt. Ihre Funktion ist bisher jedoch unbekannt. Daten aus Genomsequenzierungen zeigen eine Anreicherung in CpG Inseln von Promotoren, weshalb eine Beteiligung an der Regulation der Transkription während der zellulären Differenzierung angenommen wird. Auch ist fdC dafür bekannt von dem Enzym Thymin-DNA-Glykosylase (Tdg) erkannt und ausgeschnitten zu werden. Folglich wird angenommen, dass fdC als Intermediat während der aktiven Demethylierung auftritt. Um die Funktion der neuen epigenetischen Base fdC zu verstehen, ist es von großer Bedeutung dessen Bildung und Entfernung an definierten genomischen Positionen analysieren zu können. Im Folgenden beschreiben wir eine neue derartige Methode, die sequenzspezifische, chemische Derivatisierung von fdC mit Droplet Digital PCR kombiniert. Erste Ergebnisse zeigen, dass das Reparaturprotein Tdg nur 50\% der fdCs an einer bestimmten Position im Genom entfernt, was auf semi-permanente Eigenschaften dieser Base hinweist.
\end{abstract}

Die DNA beinhaltet, neben der Sequenzinformation, eine weitere epigenetische Informationsebene, die steuert, wie aktiv das kontrollierte Gen transkribiert wird. ${ }^{[1]}$ Neben den vier kanonischen Basen sind bisher vier weitere epigenetische Basen bekannt. ${ }^{[2]}$ Diese sind 5-Methylcytosin (5mdC), 5-Hydroxymethylcytosin (5hmdC), ${ }^{[3]}$ 5-Formylcytosin (5fdC) $)^{[4]}$ und 5-Carboxycytosin (5cadC). ${ }^{[5]}$ (Abbildung 1a) In den vergangenen Jahren trugen sensitive massenspektrometrische Methoden dazu bei die globalen Werte der epigenetischen Basen in Stammzellen, ${ }^{[4,6]}$ sowie in Geweben, einschließlich des Gehirns, zu bestimmen. ${ }^{[7]}$ Um mehr über den Gehalt und die Verteilung der epigenetischen Basen an definierten Genompositionen zu lernen, wurden verschiedene Sequenziermethoden entwickelt, ${ }^{[8]}$ wobei selektive chemische Umsetzungen der Basen unternommen wurden; ${ }^{[9]}$ manchmal in Kombination mit Bisulfitsequenzierung. ${ }^{[9 c, 10]}$ So konnten Informationen über die Verteilung der Basen zu einem bestimmten Zeitpunkt geliefert werden. Es ist jedoch ein Merkmal epigenetischer Information sich kontinuierlich zu ändern. Um einen tieferen Einblick in die Dynamik dieser epigenetischen Information an einer definierten genomischen Position zu erhalten, ist es essentiell Methoden zu entwickeln, die diese Veränderungen verfolgbar machen, beispielsweise um die zeitliche Änderung des fdCs an einer bestimmten Stelle im Genom detektieren zu können. ${ }^{[11]}$ Eine ideale Methode würde letztendlich erlauben die fdC Dynamik an unterschiedlichen genomischen Positionen simultan zu verfolgen. Als zentrale Frage stellt sich hierbei: Sind die bereits gemessenen globalen Werte, Mittelwerte verschiedener Prozesse an unterschiedlicher Positionen oder reflektieren sie was an einer individuellen Stelle passiert? Um diese Frage beantworten zu können, entwickelten wir eine sequenzspezifische, chemische Derivatisierungs-Methode. In Kombination mit Droplet Digital PCR, ermöglicht unsere Methode eine direkte Verfolgung der epigenetischen Base fdC an spezifischen Positionen im Genom von Stammzellen.

a)<smiles>Cc1cn(C)c(=O)n1N</smiles><smiles>Cn1cc(CO)c(N)n1</smiles><smiles>Cn1cc(C=O)c(N)nc1=O</smiles><smiles>Cn1cc(C(=O)O)c(N)nc1=O</smiles>

$\mathrm{mC}$

$\mathrm{hmC}$

fC

caC

b)

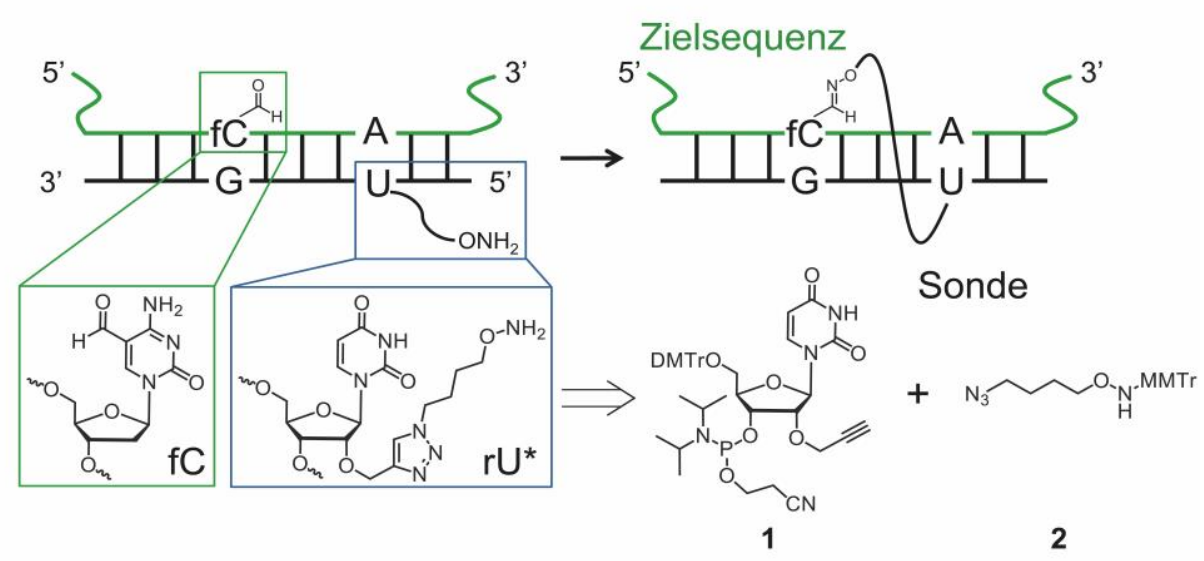

Abbildung 1. a) Strukturen der epigenetischen Cytosin-Modifikationen; b) Schematische Darstellung der fdC Detektionsstrategie und genutzte Bausteine, einschließlich der Click-Chemie basierten Assemblierung des rU* Sonden-Moleküls. 
Zur sequenzspezifischen Lokalisierung von fdC im Genom benutzen wir ein kleines Sondenoligonukleotid (Abbildung 1b, Tabelle S1), das einen Hydroxylamin-Anker enthält, der eine kovalente Bindung mit fdC eingehen kann, sodass der Sondenstrang sofort fest mit dem Zielstrang verbunden ist. ${ }^{[4]}$ Wir untersuchten systematisch verschiedene Linkerlängen, Ankerpunkte und Abstände. Die besten Ergebnisse erzielten wir mit einem Sondenoligonukleotid, in das wir ein 2'-O-propargyluridin (Phosphoramidit 1) einfügten und das Azido-C4-hydroxylamin 2 mittels $\mathrm{Cu}(\mathrm{I})$-Katalyse (Click-Reaktion) der Huisgen-Reaktion einbrachten. ${ }^{[12]}$ Wir schützten den Hydroxylamin-Baustein für die Click-Reaktion mit einer Monomethoxytrityl-Gruppe (MMTr), die im Anschluss mit Essigsäure bei Raumtemperatur entfernt wurde. Diese kurze Säurebehandlung des Sondenoligonukleotids versursachte keine merkliche Depurinierung.

Nach Festphasensynthese, Click-Modifizierung und einem finalen Aufreinigungsschritt, erhielten wir Oligonukleotide mit unterschiedlichen Sequenzen und Längen, die eine rU-Hydroxylaminbase ( $\mathrm{rU}^{\star}$ ) an verschiedenen Positionen zur Reaktion mit der fdCBase im Zielstrang, enthielten. Für nachfolgende Experimente wurden 13-nt lange Oligonukleotide angefertigt. Um festzustellen, an welcher Position der Linker am Besten mit dem fdC des Zielstranges reagiert, variierten wir die Position von rU* relativ zu fdC und untersuchten verschiedene Reaktionsbedingungen (Daten nicht gezeigt). Ausgezeichnete Ergebnisse wurden erreicht, als wir die Sonde $\mathbf{P 1}$, die $\mathrm{rU}^{*}$, exakt vier Basenpaare in 5'-Richtung relativ zu fdC enthielt, mit dem fdC Zielstrang in Gegenwart katalytischer Mengen an 4-Methoxyanilin (Abbildung 2a) hybridisierten. Mit diesem Katalysator, fand die Crosslinking-Reaktion bereits nach $24 \mathrm{~h}$ mit einer Ausbeute von über $95 \%$ statt. Ohne Katalysator konnte nur eine Ausbeute von $50 \%$ erhalten werden (Abbildung $2 b$ ).

Um die Reaktionsgeschwindigkeit zu steigern, wurden weitere Katalysatoren getestet. Die besten Ergebnisse lieferte hierbei 1,4Diaminobenzol, wodurch die Crosslinking-Reaktion von T1 und P1 bereits nach $3 \mathrm{~h}$ erfolgte (Abbildung 2c). Die Ausbildung des Doppelstranges (T1:P1) wurde mittels denaturierendem PAGE Gel analysiert und über Fluoreszenz quantifiziert (Abbildung 2d).

Wird fdC eine Base weiter entfernt von $\mathrm{rU}^{*}$ eingebaut, ohne die Sonde zu verändern, ist die Reaktion verlangsamt (Abbildung S2). Die Ergebnisse zeigen, dass $\mathrm{rU}^{\star}$, vier oder fünf Basen in 5'-Richtung zu fdC entfernt, platziert, dem Anker erlaubt die Formylgruppe des fdC über die große Furche des Doppelstranges zu erreichen (Abbildung S3).

\section{T1: 5'-GTAATGFCGCTAGG-3' P1: 3'-CATTACGCGAU*CC-5'}

a)

b)

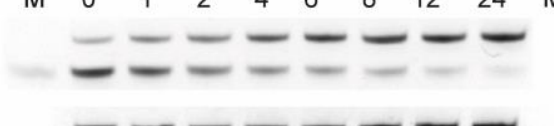

c)

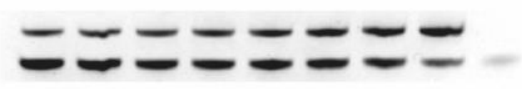

Zeit [min]

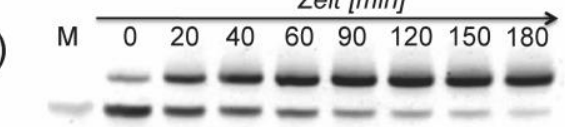

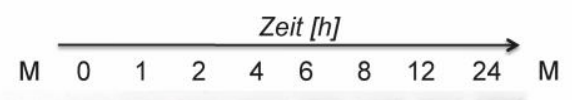

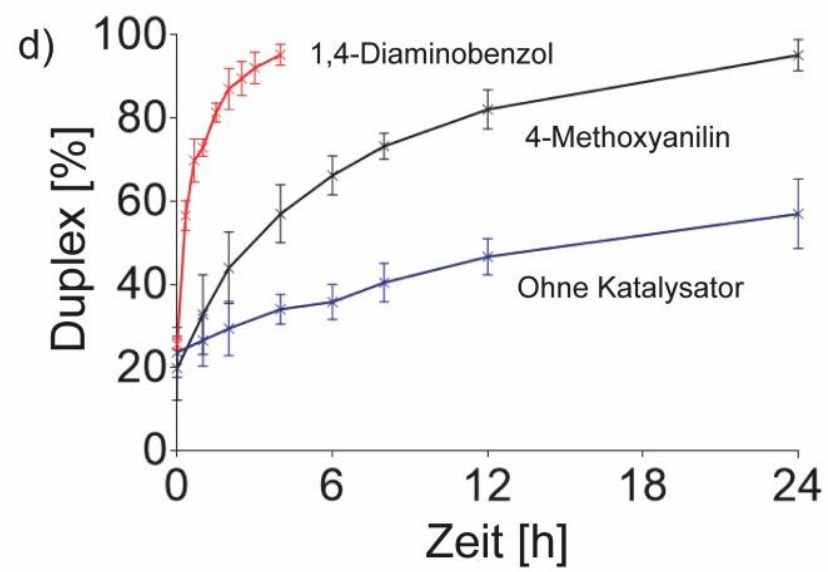

Abbildung 2. Denaturierendes PAGE Gel zeigt die Duplex-Bildung zwischen T1 und P1 bei $25^{\circ} \mathrm{C}$ : a) Mit Katalysator 4-Methoxyanilin; b) Ohne Katalysator; c) Mit Katalysator 1,4-Diaminobenzol; d) Quantifizierung der DNA-Duplex Ausbildung während der Reaktion. Schwarz: Katalysator 4-Methoxyanilin, blau: ohne Katalysator, Rot: Katalysator 1,4-Diaminobenzol. Die Fehlerbalken repräsentieren die mittlere Standardabweichung, berechnet aus dem Mittelwert dreier Replikate. Bedingungen: $2 \mu \mathrm{M}$ Oligonukleotide, $100 \mathrm{mM} \mathrm{NaCl}, 10 \mathrm{mM} \mathrm{NaOAc}$ Puffer pH 6.0, $10 \mathrm{mM}$ 4-Methoxyanilin. M = Einzelstrangmarker. Der Zeitpunkt 0 befindet sich nach dem Re-annealing.

MALDI-TOF Daten bestätigten, dass sich der Crosslink wie erwartet bildete (Abbildung S4). Im Falle des reagierten Doppelstranges T1:P1 erhielten wir die korrekte Molekülmasse mit $m / z_{\text {gefunden }} 8081,9\left(\mathrm{~m} / \mathrm{z}_{\text {berechnet }} 8084,7\right)$. Wie erwartet, führte die OximBildungsreaktion zwischen T1 und $\mathbf{P 1}$ zu einer erhöhten Schmelztemperatur des hybridisierten und reagierten Doppelstranges (Abbildung S5). Der nicht durch Crosslinking verknüpfte 13-mer Doppelstrang schmolz typischerweise bei etwa $44^{\circ} \mathrm{C}$. Nach Ausbildung des Crosslinks zeigte der Doppelstrang dagegen eine Schmelztemperatur von über $80^{\circ} \mathrm{C}$.

Da Pyrimidine mit Nukleophilen an der C6 Position in einer Michael-artigen Reaktion reagieren können, die als Basis der BisulfitSequenzierung dient, testeten wir als nächstes ob die Reaktion mit rU* auch mit anderen Pyrimidinen möglich ist (Abbildung 3). Zu unserer Zufriedenheit ergab eine Hybridisierung der $\mathrm{rU}^{*}$-Sonde mit einem dT bzw. dC, mdC, hmdC und cadC (T3-8) enthaltenden Zielstrang keine Reaktion. Eine Reaktion wurde jedoch mit einer abasischen Stelle festgestellt. Dies ist von Bedeutung, da fdC und cadC Substrate der Basenexzisionsreparatur sind und daher im Prinzip Vorläufer von abasischen Stellen sein könnten. ${ }^{[13]}$ In diesem Sinne zeigt $\mathrm{rU}^{*}$ immer die Präsenz von fdC und potentiell auch von abasische Stellen aus fdC und cadC an. Anschließend wandelten wir die Möglichkeit fdC zu detektieren in eine Methode um, einzelne fdC Basen an einer bestimmten Position in ganzen Genomen zu detektieren. Zu diesem Zweck verknüpften wir Chemie mit Droplet Digital PCR ${ }^{[14]}$ basierender Amplifikation und Datenanalyse. 


\section{T3-8: 5'-GTAATGXGCTAGG-3' P1: 3'-CATTACGCGAU*CC-5'}

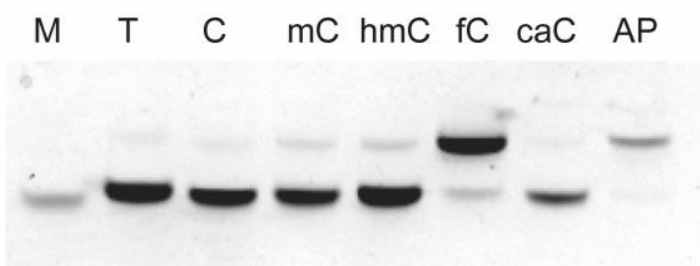

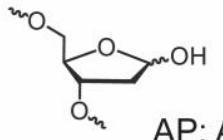

AP: Abasische Stelle

Abbildung 3. Denaturierendes PAGE Gel zeigt die Duplex-Ausbildung der Stränge T3-8 mit P1 bei $25^{\circ} \mathrm{C}$ nach $24 \mathrm{~h}$.

Zunächst wurde genomische DNA (Tg) aus murinen embryonalen Stammzellen (mESCs) zu verschiedenen Zeitpunkten während des sogenannten Primings aus naïven Stammzellen isoliert. Außerdem isolierten wir genomische DNA aus mESCs mit und ohne dem Reparaturenzym $\mathrm{Tdg}\left(\mathrm{Tdg}^{-1}\right)$, um so die Entfernung und Reparatur von fdC und cadC zu verhindern. Weiterhin isolierten wir genomische DNA aus Stammzellen ohne die drei DNA-Methyltransferasen (Dnmt1, 3a und 3b). In diesen Zellen entsteht kein mdC, weshalb sie nicht fähig sind auch die weiter oxidierten epigenetischen Basen $x d C(x=h m, f$ und ca) herzustellen. Genomische DNA hieraus fungiert in unseren Experimenten als Negativkontrolle. Analysiert wurden zwei verschiedene bereits bekannte fdC Positionen, an denen ein unterschiedlich hoher fdC Gehalt beschrieben wurde. ${ }^{[10 c]}$

Zunächst fokussierten wir uns auf die 30.020.539ste Position des Chromosoms 16 Mus musculus (MM9) im Exon 3 von 632428C04Rik. RedBS-Sequenzierungen zufolge, enthält diese Stelle zu 23\% fdC. Die zweite Stelle ist die 8.846.677 $7^{\text {ste }}$ Position des Chromosoms 15 und befindet sich in nicht-kodierender DNA. Der gleichen Studie zufolge, enthält diese Position zu 32\% fdC.

Zur Untersuchung der ersten Position, ließen wir eine $\mathrm{rU}^{*}$ enthaltende 25-mer Sonde (P2, SI) mit Tg unter 1,4-Diaminobenzol Katalyse reagieren. In Abwesenheit von fdC bildet sich keine kovalente Bindung zwischen P2 und Tg aus. Um den Überschuss an Sonde zu entfernen, luden wir den Tg:P2 Komplex auf eine NEB Monarch DNA Cleanup Säule und spülten mit Waschpuffer, um Oligonukleotide kürzer als 50-nt zu eluieren, was ungebundenem P2 entspricht. Nach dem Waschen, eluierten wir Tg:P2 mit TE Puffer. UV/Vis Analyse des Eluats zeigte ein typisches gDNA Spektrum. Als nächstes gaben wir einen 70-mer 5'-phosphorylierten Reporterstrang (R1, SI) zu, der mit einem 18-nt langen Abschnitt in direkter Nachbarschaft zum Sondenstrang hybridisiert und ligierten diese Sonde mit dem Reporter bei $60^{\circ} \mathrm{C}$ mit Ampligase, um den R1-P2 Duplex herzustellen, wie in Abbildung 4a schematisch dargestellt. Als nächstes gaben wir zwei Primerpaare zum Assay (Blaue und grüne Pfeile, Abbildung 4a) zu, um das Ligationsprodukt relativ zum Zielduplex zu vervielfältigen. Von Bedeutung ist hierbei, dass die blauen Primer lediglich das R1-P2 Hybrid der Sonde aus dem Ligationsschritt binden, während die grünen Primer die Gegenwart von gDNA signalisieren. Die Amplifikation wurde mit zwei verschiedenen TaqMan Sonden verfolgt, die eine Fluoreszenz bei 520 und $556 \mathrm{~nm}$ aufweisen. Diese relative Detektion ist notwendig, um auf die Menge an zugegebener gDNA normalisieren zu können. Da die konventionelle Real-Time PCR bei einer Differenz geringer als dem zehnfachen Unterschied ungenaue Ergebnisse liefert, nutzten wir für unsere Studien die Droplet Digital PCR. Bei dieser Methode werden kleine Tropfen gebildet, wobei im Optimalfall pro Tropfen maximal ein komplettes Analysekontrukt enthalten ist, wie in Abbildung 4a gezeigt. Die PCR Reaktionen finden in den Tropfen statt und generieren ein spezifisches Signal. Darauffolgendes Zählen der Farben jedes einzelnen Tropfens führt zu Werten, aus denen die exakte Menge an fdC, auch bei geringen Werten, berechnet werden kann. Ein repräsentativer Graph ist in Abbildung 4b gezeigt. Leere Tropfen ergeben kein PCR Signal (schwarze Punkte in Abbildung 4b). Tropfen, die nur Tg enthalten, ergeben das PCR Signal der grünen Primer (grüne Punkte in Abbildung 4b). Blaue Signale werden erhalten, wenn das ligierte Produkt R1-P2 während des Ligationsprozesses $\left(60^{\circ} \mathrm{C}\right.$ für $10 \mathrm{~h}$ ) von Tg dissoziiert. Rote Signale werden schließlich aus Tropfen generiert, die beide PCR Produkte enthalten. Für die Berechnung der Werte wird auf die Hintergrundinformation verwiesen.

Mit dieser Methode untersuchten wir zunächst Stammzellen ohne Tdg Enzym ( $\left.\mathrm{Tdg}^{-/}\right)$. Ein eher hoher Wert von $28.5 \% \mathrm{fdC} \mathrm{konnte}$ an der ersten Position gemessen werden (Abbildung 4c), was mit den Ergebnissen aus redBS-Sequenzierungen gut übereinstimmt. ${ }^{[10 c]}$ Als wir jedoch das Experiment in Stammzellen mit intaktem Tdg Reparaturenzym durchführten $\left(\mathrm{Tdg}^{+/-}\right)$, wurden an dieser Position nur noch 15.7\% gemessen (Abbildung 4c). Dies ist von großer Bedeutung, da es zeigt, dass Tdg nur die Hälfte der fdCs an einer bestimmten Stelle entfernt und ungewöhnlich da Reparaturenzyme dafür bekannt sind quasi alle möglichen Substrate zu finden. Dieses Ergebnis unterstreicht die hohe Dynamik der fdC Bildung und Reparatur an einer bestimmten Position im Genom. Als wir den fdC Gehalt an dieser Stelle in Stammzellen ohne DNA-Methyltransferase (Dnmt TKO) untersuchten, fiel der fdC Wert wie erwartet auf etwa $5 \%$. Dies zeigt, dass die gemessenen Werte in den $\mathrm{Tdg}^{+/}$Zellen real und keine Artefakte sind. Um weiterhin aufzuklären, ob die fdC Werte einzelner Positionen (Abbildung 4c) den globalen genomischen fdC-Werten folgen, quantifizierten wir zudem die absoluten Werte an $\mathrm{fdC}$ in diesen Zellen (Abbildung 4d). Diese globalen Daten stehen in guter Übereinstimmung mit den Daten der fdC Quantifizierungen einzelner Positionen. Aufgrund unserer neuen Daten ist es eher unwahrscheinlich, dass fdC an einer Stelle komplett entfernt und an einer anderen gänzlich vor der Reparatur geschützt wird. Stattdessen wird fdC an einer Position in einer Zellpopulation eher teilweise entfernt. Alternativ, könnte Tdg fdC unterschiedlich auf den beiden Chromosomen entfernen, was jedoch weiterer Untersuchung bedarf. 
a)
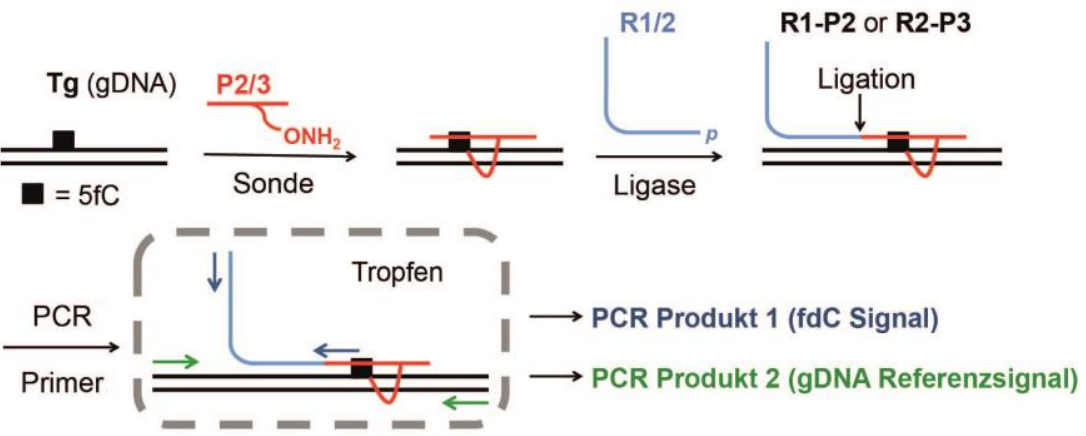

b)

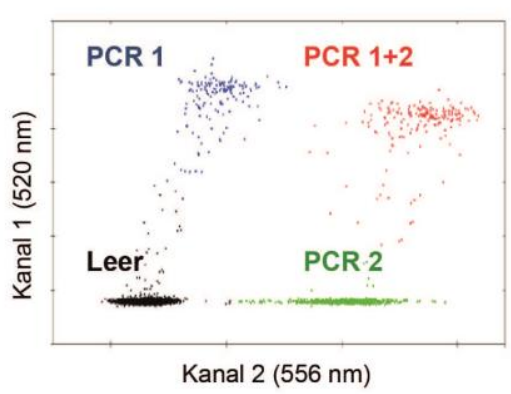

c)

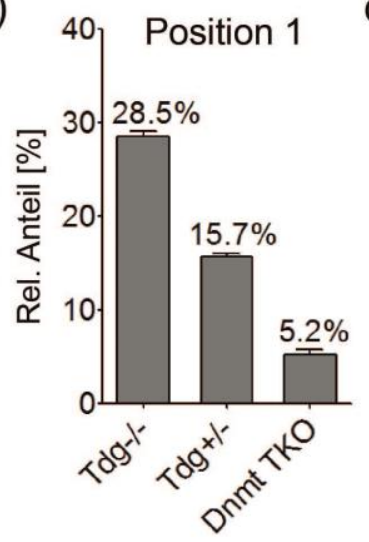

d)

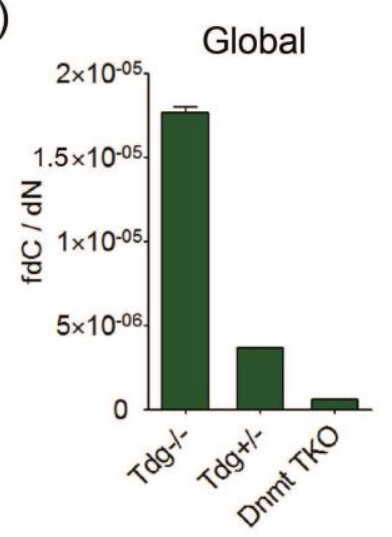

e) Position 2 f)

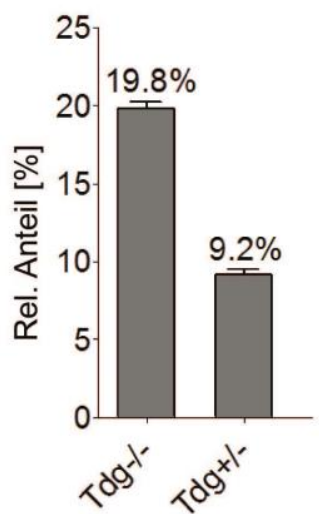

Position 1

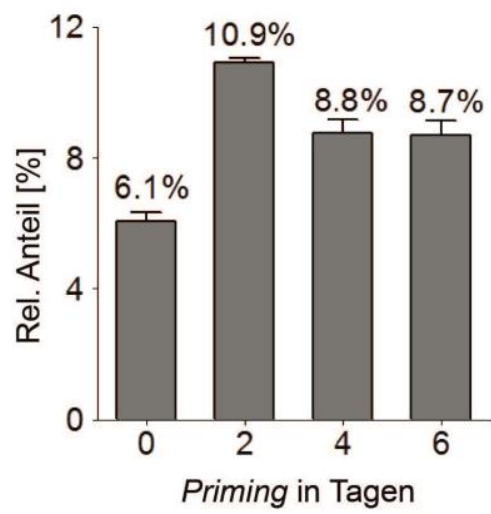

g)
Global

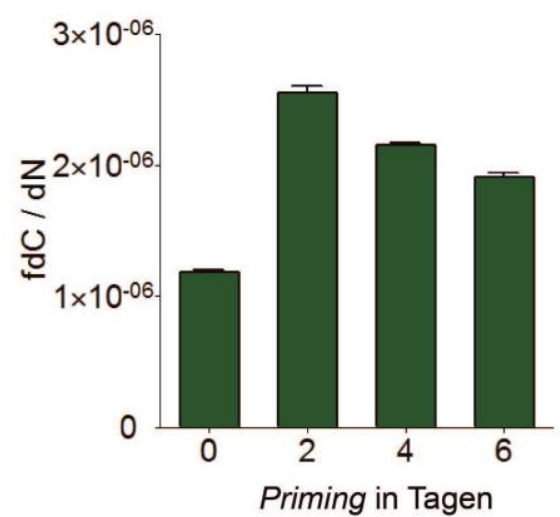

Abbildung 4. Die fdC Sequenzierungsmethode: a) Schematische Repräsentation der Methode, schwarze Linie: gDNA; rote Segmente: fdC Sonde; blaue Segmente: Reporterstränge; Pfeile: PCR Primerpaare; b) Typischer 2-D Plot der Tropfen-Fluoreszenz; c) Cluster-Verhältnisse der Position 1 in Tdg ${ }^{-/}$, Tdg ${ }^{+/-}$und Dnmt TKO mES Zellen; d) Globale fdC Quantifizierung in Tdg ${ }^{-/}$, Tdg ${ }^{+/-}$und Dnmt TKO mES Zellen mittels unserer LC-MS Methode; e) Cluster-Verhältnisse der Position 2 in $\mathrm{Tdg}^{-/-}$und $\mathrm{Tdg}^{+/}$mES Zellen; f) Cluster-Verhältnisse der Position 1 in Wildtyp mES Zellen an verschiedenen Tagen während des Primings; g) Globale Quantifizierungsdaten der Wildtyp mES Zellen gemessen durch LC-MS.

Um unsere Daten verifizieren zu können, wiederholten wir die Tdg-Studie an einer zweiten Position (8,846,677 ste $^{\text {Nukleosid des }}$ Chromosoms 15). Für diese Stelle, entwarfen wir einen neuen Sondenstrang P3, einen neuen Reporterstrang R2 und führten die ddPCR erneut mit zwei Primerpaaren durch (Abbildung S5). Vergleicht man die Daten aus Tdg ${ }^{-/-}$Zellen mit den Daten aus Tdg ${ }^{+/-}$Zellen, ist an dieser Position wieder ein 50\%iger Rückgang des fdC Gehalts erkennbar. Dies ist in voller Übereinstimmung mit den Daten der ersten Position (Abbildung 4e).

Schließlich führten wir eine Untersuchung durch, bei der wir die Entwicklung von fdC an der ersten Position während des Primings von Stammzellen aus naïven Zellen beobachteten (Abbildung 4f). An dieser Position ist ein Anstieg der fdC Werte, besonders in der frühen Priming-Phase, zu beobachten. Es folgen ein geringer Abfall und schließlich stabile Werte (Abbildung 4f), was wiederrum in Übereinstimmung mit den globalen Messwerten steht, die wir durch unsere bereits beschriebene Methode bestimmten (Abbildung $4 \mathrm{~g}$ ).

Die Tatsache, dass unsere Methode in der Lage ist, die beschriebenen globalen Werte an einer einzelnen genomischen Position zu reproduzieren, stimmt uns positiv, dass unsere Methode erlaubt, verlässlich wiederzugeben was an einer definierten Stelle geschieht. Da die Daten der individuellen Positionen und die globalen Werte korrelieren, haben wir erste Hinweise, dass die beschriebenen globalen Trends tatsächlich wiedergeben, was an einer einzigen fdC enthaltenden Position geschieht, anstatt den Mittelwert unterschiedlicher Dynamiken an verschiedenen Positionen abzubilden. Ein interessantes Ergebnis dieser Studie ist hierbei, dass das Reparaturenzym Tdg nur die Hälfte der fdC Basen an einer bestimmten Stelle im Genom einer mESC Population entfernt, was auf semi-permanente Eigenschaften der Base an definierten genomischen Positionen schließen lässt. 


\section{Experimenteller Teil}

Crosslink der Sonde gDNA Lösung (1.2 $\mu \mathrm{g})$, fdC Sonde (1 $\mu \mathrm{M}, 2 \mu \mathrm{L}), \mathrm{NaH}_{2} \mathrm{PO}_{4}-\mathrm{Na}_{2} \mathrm{HPO}_{4}$ Puffer (200 mM, pH = 6.0, $\left.2 \mu \mathrm{L}\right)$, NaCl aq. (1.5 M, $\left.2 \mu \mathrm{L}\right)$ und $d d \mathrm{H}_{2} \mathrm{O}$ wurden zu einem Endvolumen von $18 \mu \mathrm{L}$ zusammen gegeben. Die Mischung wurde 3 min bei $95^{\circ} \mathrm{C}$ erhitzt und schnell auf $25^{\circ} \mathrm{C}$ abgekühlt. $1,4-$ Benzoldiamin aq. (10 mM, $2 \mu \mathrm{L}$ ) wurde zugegeben und das Reaktionsgefäß $6 \mathrm{~h}$ bei $25^{\circ} \mathrm{C}$ geschüttelt. Vor Aufreinigung mit dem NEB Monarch PCR DNA Cleanup Kit, wurde die Reaktionsmischung mit $\mathrm{Na}_{2} \mathrm{HPO}_{4}$ aq. (200 mM, $\left.40 \mu \mathrm{L}\right)$ neutralisiert.

Ligation Die zuvor beschriebene gDNA Lösung (300 ng), Reporterstrang ( $20 \mathrm{nM}, 1 \mu \mathrm{L})$ ), Ampligase Reaktionspuffer (10×, $2 \mu \mathrm{L})$, Ampligase von Epicentre $(5 \mathrm{U} / \mu \mathrm{L}, 2 \mu \mathrm{L}, 10 \mathrm{U})$ und $d d \mathrm{H}_{2} \mathrm{O}$ wurden bis zu einem Endvolumen von $20 \mu \mathrm{L}$ zusammen gegeben. Die Mischung wurde für 3 min bei $95^{\circ} \mathrm{C}$ erhitzt, dann $1 \mathrm{~min}$ bei $94^{\circ} \mathrm{C}, 1 \mathrm{~h}$ für $60^{\circ} \mathrm{C}$ und wieder auf $94^{\circ} \mathrm{C}(10$ Zyklen) temperiert. Danach wurde das Reaktionsgemisch mit Tris-HCl Puffer $(200 \mathrm{mM}, \mathrm{pH}=7.6$, $50 \mu \mathrm{L})$ verdünnt, bevor es mittels NEB Monarch PCR DNA Cleanup Kit gereinigt wurde.

Droplet Digital PCR Die ddPCR wurde auf einem Bio-Rad QX100 ddPCR System durchgeführt. Für die Reaktion wurden gDNA (6 ng), vier Primer (jeweils $18 \mu \mathrm{M}, 1 \mu \mathrm{L}$ ), zwei TaqMan Sonden (jeweils $5 \mu \mathrm{M}, 1 \mu \mathrm{L}$ ), digital PCR Supermix für Sonden (kein dUTP, $2 \times, 10 \mu \mathrm{L}$ ) und dd $\mathrm{H}_{2} \mathrm{O}$ gemischt; das Endvolumen betrug $20 \mu \mathrm{L}$. PCR-Zyklus: $95^{\circ} \mathrm{C}$ für $10 \mathrm{~min}, 94^{\circ} \mathrm{C}$ für $30 \mathrm{sec}$ und $64^{\circ} \mathrm{C}$ für $1 \mathrm{~min}\left(35\right.$ Zyklen), dann folgten $98^{\circ} \mathrm{C}$ für 10 min und schließlich wurde mit $2^{\circ} \mathrm{C} / \mathrm{s}$ auf $12^{\circ} \mathrm{C}$ abgekühlt. Eine detaillierte Beschreibung ist den Hintergrundinformationen zu entnehmen.

\section{Danksagung}

Wir danken K. Hufnagel für die Herstellung der Phosphoramidite der verwendeten epigenetischen Basen. Dieses Projekt wurde durch die Deutsche Forschungsgemeinschaft SFB1032 und den Excellence Cluster CiPS ${ }^{\mathrm{M}}$ (EXC114) gefördert. Weiterhin wurde das Projekt durch den European Union's Horizon 2020 Research und das Innovation Program Under Grant Agreement Nr. 642023 (ITN clickgene) unterstützt.

\section{Stichworte: Epigenetische Base • Click-Chemie • 5-Formylcytosine $・$ Genomische DNA $・$ Droplet Digital PCR}

[1] P. A. Jones, Nat. Rev. Genet. 2012, 13, 484-492.

[2] T. Carell, C. Brandmayr, A. Hienzsch, M. Müller, D. Pearson, V. Reiter, I. Thoma, P. Thumbs, M. Wagner, Angew. Chem., Int. Ed. 2012, 51, 7110-7131; Angew. Chem. 2012, 124, 7220-7242.

[3] a) S. Kriaucionis, N. Heintz, Science 2009, 324, 929-930; b) M. Tahiliani, K. P. Koh, Y. Shen, W. A. Pastor, H. Bandukwala, Y. Brudno, S. Agarwal, L. M. lyer, D. R. Liu, L. Aravind, A. Rao, Science 2009, 324, 930-935.

[4] T. Pfaffeneder, B. Hackner, M. Truss, M. Münzel, M. Müller, C. Deiml, C. Hagemeier, T. Carell, Angew. Chem., Int. Ed. 2011, 50, 7008-7012; Angew. Chem. 2011, 123, 7146-7150.

[5] a) S. Ito, L. Shen, Q. Dai, S. C. Wu, L. B. Collins, J. A. Swenberg, C. He, Y. Zhang, Science 2011, 333, 1300-1303; b) Y.-F. He, B.-Z. Li, Z. Li, P. Liu, Y. Wang, Q. Tang, J. Ding, Y. Jia, Z. Chen, L. Li, Y. Sun, X. Li, Q. Dai, C.-X. Song, K. Zhang, C. He, G.-L. Xu, Science 2011, 333, $1303-1307$.

[6] S. Schiesser, B. Hackner, T. Pfaffeneder, M. Müller, C. Hagemeier, M. Truss, T. Carell, Angew. Chem., Int. Ed. 2012, 51, 6516-6520; Angew. Chem. 2012, $124,6622-6626$

[7] a) M. Münzel, D. Globisch, T. Brückl, M. Wagner, V. Welzmiller, S. Michalakis, M. Müller, M. Biel, T. Carell, Angew. Chem., Int. Ed. 2010, 49, 5375-5377; Angew. Chem. 2010, 122, 5503-5505; b) D. Globisch, M. Münzel, M. Müller, S. Michalakis, M. Wagner, S. Koch, T. Brückl, M. Biel, T. Carell, PLoS ONE 2010, 5 , e15367; c) M. Wagner, J. Steinbacher, T. F. J. Kraus, S. Michalakis, B. Hackner, T. Pfaffeneder, A. Perera, M. Müller, A. Giese, H. A. Kretzschmar, T. Carell, Angew. Chem., Int. Ed. 2015, 54, 12511-12514; Angew. Chem. 2015, 127, 12691-12695.

[8] a) N. Plongthongkum, D. H. Diep, K. Zhang, Nat. Rev. Genet. 2014, 15, 647-661; b) M. J. Booth, E.-A. Raiber, S. Balasubramanian, Chem. Rev. 2015, 115, 2240-2254.

[9] a) W. A. Pastor, U. J. Pape, Y. Huang, H. R. Henderson, R. Lister, M. Ko, E. M. McLoughlin, Y. Brudno, S. Mahapatra, P. Kapranov, M. Tahiliani, G. Q. Daley, X. S. Liu, J. R. Ecker, P. M. Milos, S. Agarwal, A. Rao, Nature 2011, 473, 394-397; b) E.-A. Raiber, D. Beraldi, G. Ficz, H. Burgess, M. Branco, P. Murat, D. Oxley, M. Booth, W. Reik, S. Balasubramanian, Genome Biol. 2012, 13, R69; c) C.-X. Song, Keith E. Szulwach, Q. Dai, Y. Fu, S.-Q. Mao, L. Lin, C. Street, Y. Li, M. Poidevin, H. Wu, J. Gao, P. Liu, L. Li, G.-L. Xu, P. Jin, C. He, Cell 2013, 153, 678-691; d) B. Xia, D. Han, X. Lu, Z. Sun, A. Zhou, Q. Yin, H. Zeng, M. Liu, X. Jiang, W. Xie, C. He, C. Yi, Nat. Methods 2015, 12, 1047-1050

[10] a) M. Yu, Gary C. Hon, Keith E. Szulwach, C.-X. Song, L. Zhang, A. Kim, X. Li, Q. Dai, Y. Shen, B. Park, J.-H. Min, P. Jin, B. Ren, C. He, Cell 2012, 149, 1368-1380; b) M. J. Booth, M. R. Branco, G. Ficz, D. Oxley, F. Krueger, W. Reik, S. Balasubramanian, Science 2012, 336, 934-937; c) M. J. Booth, G. Marsico, M. Bachman, D. Beraldi, S. Balasubramanian, Nat. Chem. 2014, 6, 435-440; d) X. Lu, C.-X. Song, K. Szulwach, Z. Wang, P. Weidenbacher, P. Jin, C. He, J. Am. Chem. Soc. 2013, 135, 9315-9317.

[11] a) A. Nomura, K. Sugizaki, H. Yanagisawa, A. Okamoto, Chem. Commun. 2011, 47, 8277-8279; b) J. Duprey, G. A. Bullen, Z.-Y. Zhao, D. M. Bassani, A. F. A. Peacock, J. Wilkie, J. H. R. Tucker, ACS Chem. Bio. 2016, 11, 717-721.

[12] a) P. M. E. Gramlich, S. Warncke, J. Gierlich, T. Carell, Angew. Chem., Int. Ed. 2008, 47, 3442-3444; Angew. Chem. 2008, 120, 3491-3493.; b) J. Willibald, J. Harder, K. Sparrer, K.-K. Conzelmann, T. Carell, J. Am. Chem. Soc. 2012, 134, 12330-12333.

[13] A. Maiti, A. C. Drohat, J. Biol. Chem. 2011, 286, 35334-35338.

[14] B. J. Hindson, K. D. Ness, D. A. Masquelier, P. Belgrader, N. J. Heredia, A. J. Makarewicz, I. J. Bright, M. Y. Lucero, A. L. Hiddessen, T. C. Legler, T. K. Kitano, M. R. Hodel, J. F. Petersen, P. W. Wyatt, E. R. Steenblock, P. H. Shah, L. J. Bousse, C. B. Troup, J. C. Mellen, D. K. Wittmann, N. G. Erndt, T. H. Cauley, R. T. Koehler, A. P. So, S. Dube, K. A. Rose, L. Montesclaros, S. Wang, D. P. Stumbo, S. P. Hodges, S. Romine, F. P. Milanovich, H. E. White, J. F. Regan, G. A. Karlin-Neumann, C. M. Hindson, S. Saxonov, B. W. Colston, Anal. Chem. 2011, 83, 8604-8610.

[15] M. Wendeler, L. Grinberg, X. Wang, P. E. Dawson, M. Baca, Bioconjugate Chem. 2014, 25, 93-101. 


\section{Table of contents}

1. General methods of organic synthesis

2. Synthesis of the hydroxylamine linker

3. ${ }^{1} \mathrm{H}-\mathrm{NMR}$ spectra of the linker

4. General methods for oligonucleotide synthesis

5. Crosslinking studies with the synthesized strands

6. Experimental details of the genomic fdC profiling study

7. Quantification modeling

8. Droplet digital PCR data 


\section{General methods of organic synthesis}

Chemicals were purchased from Sigma-Aldrich and used without further purification. The solvents for organic synthesis were of reagent grade and purified by distillation. Solutions were concentrated in vacuo on a Heidolph rotary evaporator with a Vario PC2001 diaphragm pump by Vacuubrand. All mixed solvent systems are reported as v/v solutions. All reactions were monitored by thin-layer chromatography (TLC), performed on Merck 60 (silica gel $\mathrm{F}_{254}$ ) plates. Chromatographic purification of products was accomplished using flash column chromatography on silica gel (230-400 mesh) purchased from Merck.

${ }^{1} \mathrm{H}$ - and ${ }^{13} \mathrm{C}-\mathrm{NMR}$ spectra were recorded in deuterated solvents on Bruker ARX 400 spectrometers and calibrated to the residual solvent peak. Chemical shifts $(\delta, \mathrm{ppm})$ are quoted relative to the residual solvent peak as internal standard and coupling constants $(J)$ are corrected and quoted to the nearest $0.1 \mathrm{~Hz}$. Multiplicities are abbreviated as follows: $\mathrm{s}=$ singlet, $\mathrm{d}=$ doublet, $\mathrm{t}=$ triplet, $\mathrm{m}=$ multiplet.

\section{Synthesis of the hydroxylamine linker}

\section{$O$-(4-Azidobutyl)hydroxylamine 4}

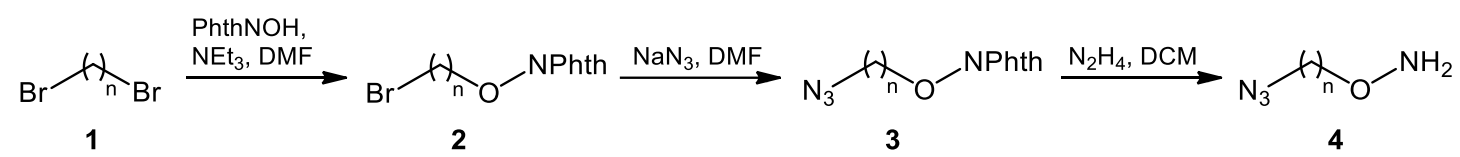

1,4-Dibromobutane 1 (5.9 mL, $49.4 \mathrm{mmol}, 2.0$ eq.) was added to a solution of $N$-hydroxyphthalimide (PhthNOH, $4.0 \mathrm{~g}, 24.5 \mathrm{mmol}, 1.0 \mathrm{eq}$.) and triethylamine (7.5 $\mathrm{mL}, 53.6 \mathrm{mmol}, 2.2$ eq.) in anhydrous dimethylformamide. The mixture was stirred at room temperature for $24 \mathrm{~h}$. The reaction was diluted with water, and the aqueous phase was extracted three times with ethyl acetate. The combined organic phases were dried over $\mathrm{MgSO}_{4}$, filtered and concentrated to give the crude product 2 (5.02 g, 16.9 mmol, 0.69 eq.) as a white solid. The residue was dissolved in anhydrous dimethylformamide and sodium azide (1.32 g, $20.6 \mathrm{mmol}, 0.85$ eq. $)$ was added. The mixture was stirred at room temperature for $2 \mathrm{~h}$, diluted with water and extracted with ethyl acetate three times. The combined organic phases were dried over $\mathrm{MgSO}_{4}$, filtered and concentrated. The crude was purified by flash chromatography on silica gel (iso-hexane/ethyl acetate $10: 1 \rightarrow 2: 1)$ to give $3(3.97 \mathrm{~g}, 15.2 \mathrm{mmol}, 0.62 \mathrm{eq}$.) as a yellow oil. The oil was redissolved in hydrazine monohydrate $(1.1 \mathrm{~mL}, 22.8 \mathrm{mmol}$, 0.93 eq.) and dichloromethane $(10 \mathrm{~mL})$. The mixture was stirred at room temperature for $24 \mathrm{~h}$ and then filtered. The solution was diluted with dichloromethane and washed with $\mathrm{NaCl}$ aq. three times. The combined organic phases were dried over $\mathrm{MgSO}_{4}$, 
filtered and concentrated to give $4(1.81 \mathrm{~g}, 13.9 \mathrm{mmol}, 57 \%$ yield over three steps $)$ as a colorless oil.

$\boldsymbol{R}_{\mathrm{f}}=0.42(\mathrm{DCM} / \mathrm{MeOH} 10: 1)$.

${ }^{1} \mathbf{H}-\mathbf{N M R}\left(400 \mathrm{MHz}, \mathrm{CDCl}_{3}\right): \delta=3.70\left(\mathrm{t},{ }^{3} \mathrm{~J}_{\mathrm{H}, \mathrm{H}}=5.6 \mathrm{~Hz}, 2 \mathrm{H}, \mathrm{O}-\mathbf{C H}_{\mathbf{2}}-\mathrm{CH}_{2}\right), 3.38(\mathrm{t}$, $\left.{ }^{3} J_{\mathrm{H}, \mathrm{H}}=6.4 \mathrm{~Hz}, 2 \mathrm{H}, \underline{\mathrm{CH}}_{2}-\mathrm{N}_{3}\right), 1.68-1.64\left(\mathrm{~m}, 4 \mathrm{H}, \mathrm{CH}_{2}-\mathrm{CH}_{2}-\mathrm{C}_{2}-\mathrm{CH}_{2}\right)$.

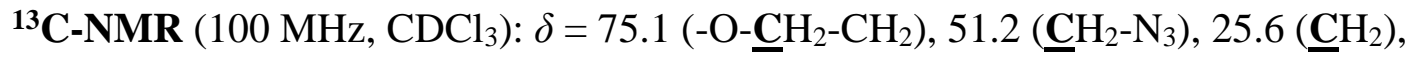
$25.5\left(\underline{\mathrm{CH}}_{2}\right)$.

HRMS (ESI+): calculated for $\mathrm{C}_{4} \mathrm{H}_{11} \mathrm{ON}_{4}{ }^{+}[\mathrm{M}+\mathrm{H}]^{+}: 131.0927$, found: 131.0928 .

\section{$O$-(4-Azidobutyl)- $N$-[(4-methoxyphenyl)diphenylmethyl]hydroxylamine (5)}<smiles>[14CH3][14CH2]NO[14C]N</smiles>

5

$O$-(4-Azidobutyl)hydroxylamine 4 (1.88 g, $14.4 \mathrm{mmol}, 1.0$ eq.) was dissolved in anhydrous dichloromethane (40 mL). 4-Monomethoxytritylchloride (MMTr-Cl, 4.91 $\mathrm{g}, 15.9 \mathrm{mmol}, 1.1 \mathrm{eq}$.) and diisopropylethylamine (5.0 mL, $28.9 \mathrm{mmol}, 2.0$ eq.) was added to the mixture at $0^{\circ} \mathrm{C}$. The reaction was stirred at room temperature for $2 \mathrm{~h}$, diluted with dichloromethane, washed with saturated $\mathrm{NaHCO}_{3}$, dried over $\mathrm{MgSO}_{4}$, filtered and concentrated. The crude was purified by flash chromatography on silica gel (iso-hexanes/ethyl acetate $15: 1+3 \%$ triethylamine) to give 5 (4.89 4g, $12.2 \mathrm{mmol}$, $84 \%)$ as a yellowish oil.

$\boldsymbol{R}_{\mathrm{f}}=0.64$ (iso-hexane/ ethyl acetate $10: 1+3 \%$ triethylamine).

${ }^{1} \mathbf{H}-\mathbf{N M R}\left(400 \mathrm{MHz}, \mathrm{CDCl}_{3}\right): \delta=7.31-7.18\left(\mathrm{~m}, 12 \mathrm{H}, 12 \times \mathrm{C}_{\mathrm{Ar}} \underline{\mathbf{H}}\right), 6.79\left(\mathrm{~d},{ }^{3} J_{\mathrm{H}, \mathrm{H}}=8.8\right.$ $\left.\mathrm{Hz}, 2 \mathrm{H}, 2 \times \mathrm{CH}_{3}-\mathrm{O}-\mathrm{C}-\mathrm{C} \underline{\mathbf{H}}\right), 3.76\left(\mathrm{~s}, 3 \mathrm{H}, \mathrm{O}-\mathbf{C H}_{3}\right), 3.65\left(\mathrm{t},{ }^{3} J_{\mathrm{H}, \mathrm{H}}=6.0 \mathrm{~Hz}, 2 \mathrm{H}\right.$, $\left.\mathrm{O}-\underline{C}_{2}-C_{2}\right), 3.05\left(\mathrm{t},{ }^{3} J_{\mathrm{H}, \mathrm{H}}=6.8 \mathrm{~Hz}, 2 \mathrm{H}, \mathrm{N}_{3}-\underline{C}_{2}\right), 1.52-1.37 \quad(\mathrm{~m}, 4 \mathrm{H}$, $\left.\mathrm{N}_{3}-\mathrm{CH}_{2}-\mathrm{CH}_{2}-\underline{\mathrm{C}}_{2}-\mathrm{CH}_{2}\right)$.

${ }^{13} \mathbf{C}$-NMR $\left(100 \mathrm{MHz}, \mathrm{CDCl}_{3}\right): \delta=158.3\left(\mathrm{CH}_{3}-\mathrm{O}-\underline{\mathbf{C}}\right), 144.6\left(2 \times \underline{\mathbf{C}}_{\mathrm{Ar}}\right), 136.6\left(\underline{\mathbf{C}}_{\mathrm{Ar}}\right)$, $130.2\left(2 \times \underline{\mathbf{C}}_{\mathrm{Ar}}\right), 129.0(4 \times \underline{\mathbf{C}} \underline{\mathrm{Ar}}), 127.6(4 \times \underline{\mathbf{C}} \underline{\mathrm{Ar}}), 126.7\left(2 \times \underline{\mathbf{C}}_{\mathrm{Ar}}\right), 112.9\left(2 \times \underline{\mathbf{C}}_{\mathrm{Ar}}\right)$, $77.2(\mathrm{O}-\mathrm{NH}-\underline{\mathbf{C}}), 73.2\left(\mathrm{O}-\underline{\mathbf{C}} \mathrm{H}_{2}\right), 55.2\left(\mathrm{O}-\underline{\mathbf{C}} \mathrm{H}_{3}\right), 51.1\left(\mathrm{~N}_{3}-\underline{\mathbf{C H}}_{2}\right), 25.8\left(\mathrm{~N}_{3}-\mathrm{CH}_{2}-\underline{\mathbf{C}} \mathrm{H}_{2}\right)$, $25.5\left(\mathrm{O}-\mathrm{CH}_{2}-\underline{\mathrm{CH}_{2}}\right)$.

HRMS (ESI-): calculated for $\mathrm{C}_{25} \mathrm{H}_{27} \mathrm{O}_{4} \mathrm{~N}_{4}{ }^{-}\left[\mathrm{M}+\mathrm{HCO}_{2}\right]^{-}$: 447.2038, found: 447.2040. 


\section{3. ${ }^{1} \mathrm{H}-\mathrm{NMR}$ spectra of the linker}
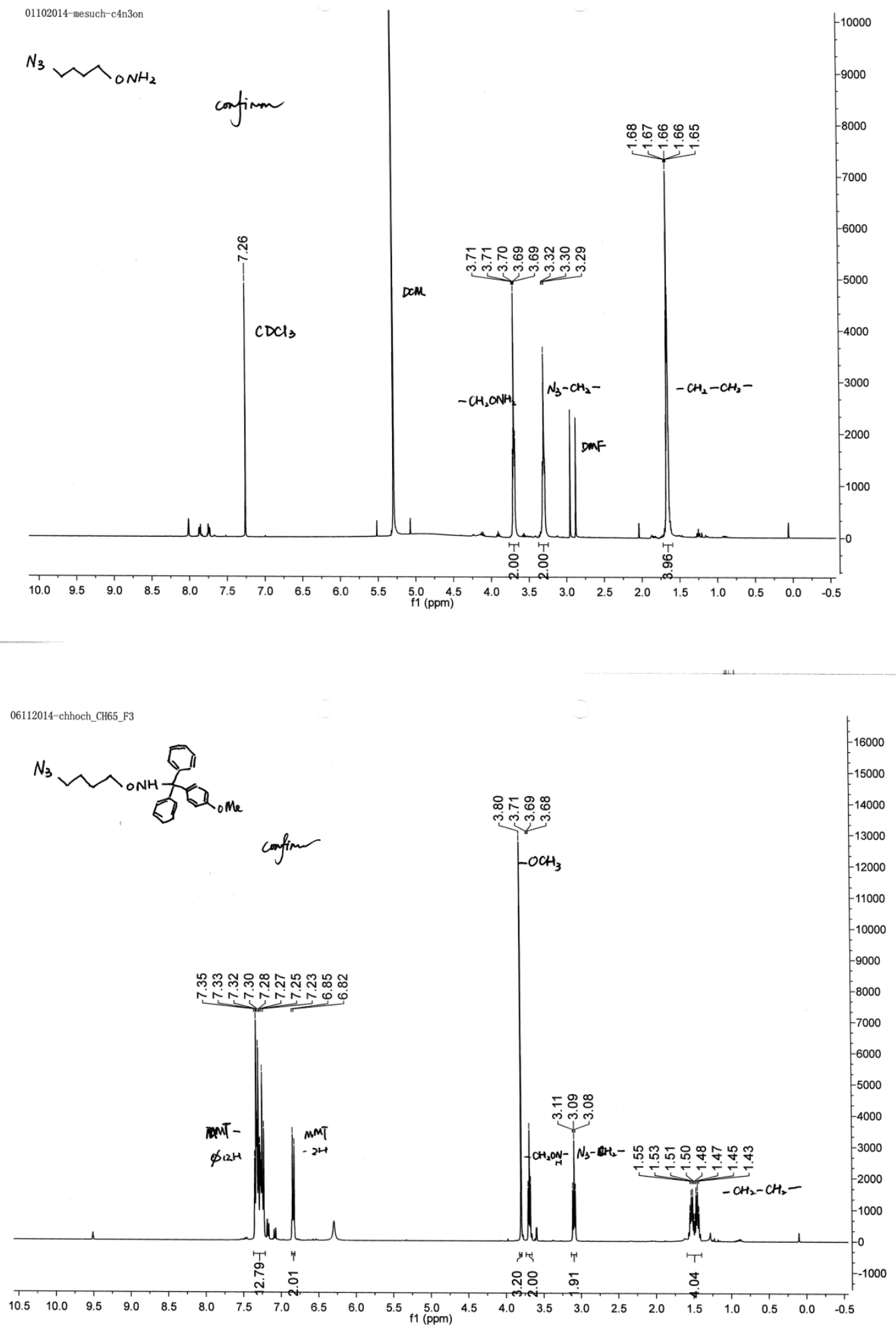


\section{General methods for oligonucleotide synthesis}

DNA Oligonucleotide synthesis was performed on an Applied Biosystems Incorporated 394 automated synthesizer. Phosphoramidites and solid supports columns were purchased from Glen Research, Link Technology, and ChemGene Corporation. Oligodeoxynucleotides were synthesized in a $1 \mu \mathrm{mol}$ scale with standard DNA synthesis cycles (trityl off mode). Coupling time for modified nucleosides was extended to $10 \mathrm{~min}$. The oligonucleotide was cleaved using conc. ammonium hydroxide aq. at $25^{\circ} \mathrm{C}$ for $17 \mathrm{~h}$. The aqueous solution was then collected and evaporated in a SpeedVac concentrator, and the pellet was redissolved in $\mathrm{ddH}_{2} \mathrm{O}$.

Analytical RP-HPLC was performed using a Macherey-Nagel Nucleodur 100-3 C18ec column on 2695 Separation Module equipped with a Waters Alliance 2996 Photodiode Array Detector using a flow of $0.5 \mathrm{~mL} / \mathrm{min}$. Semi-preparative RP-HPLC was performed using a Macherey-Nagel C18 column $(5 \mathrm{~mm}, 9.4 \times 250 \mathrm{~mm})$ on Waters Breeze 2487 Dual $\lambda$ Array Detector, 1525 Binary HPLC Pump. Conditions: Buffer A, 0.1 M TEAA (triethylammonium acetate) in water; buffer B, 0.1 M TEAA in $80 \%$ acetonitrile.

The purified fractions were concentrated and characterized by Matrix Assisted Laser Desorption Ionization Time of Flight (MALDI-TOF) on a Bruker Daltonics Autoflex II instrument. The concentration of the oligonucleotide solutions was calculated from the UV absorbance at $260 \mathrm{~nm}$ on a Nanodrop ND-1000 spectrophotometer. Extinction coefficients of the oligonucleotides at $260 \mathrm{~nm}$ were calculated by addition of the extinction coefficients of the individual nucleobases: dA $15.0 \mathrm{~L} /(\mathrm{mmol} \cdot \mathrm{cm}), \mathrm{dC} 7.1$ $\mathrm{L} /(\mathrm{mmol} \cdot \mathrm{cm}), \mathrm{dG} 12.0 \mathrm{~L} /(\mathrm{mmol} \cdot \mathrm{cm}), \mathrm{dT} 8.4 \mathrm{~L} /(\mathrm{mmol} \cdot \mathrm{cm}), \mathrm{mdC} 7.8 \mathrm{~L} /(\mathrm{mmol} \cdot \mathrm{cm})$, hmdC $8.7 \mathrm{~L} /(\mathrm{mmol} \cdot \mathrm{cm})$, fdC $11.3 \mathrm{~L} /(\mathrm{mmol} \cdot \mathrm{cm})$, cadC $7.1 \mathrm{~L} /(\mathrm{mmol} \cdot \mathrm{cm})$. The 1,2,3-triazole and abasic monomer are transparent at $260 \mathrm{~nm}$.

\section{Click reaction on the solid support with azide linkers and deprotection}

After solid phase synthesis $(0.2 \mu \mathrm{mol}$ scale, approx. 50\% yield for 13 mer, calculated as $0.1 \mu \mathrm{mol})$, the solid support was suspended in dimethyl sulfoxide $(80 \mu \mathrm{L})$ and acetonitrile $(25 \mu \mathrm{L})$. To the mixture, $\mathrm{CuSO}_{4}$ aq. (100 mM, $50 \mu \mathrm{L}, 5.0 \mu \mathrm{mol}, 50$ eq.), sodium ascorbate aq. (500 mM, $20 \mu \mathrm{L}, 10 \mu \mathrm{mol}, 100$ eq.), $N, N$-diisopropylethylamine solution in acetonitrile ( $200 \mathrm{mM}, 75 \mu \mathrm{L}, 15 \mu \mathrm{mol}, 150$ eq.), solution of $\mathbf{5}$ in dimethyl sulfoxide ( $100 \mathrm{mM}, 50 \mu \mathrm{L}, 5.0 \mu \mathrm{mol}, 50$ eq.) were added. The reaction was conducted at $25{ }^{\circ} \mathrm{C}$ for $24 \mathrm{~h}$. Afterwards, the solid support was washed with dimethyl sulfoxide, dilute $\mathrm{NaHCO}_{3}$ aq., acetonitrile, ether and air-dried to a powder. The solid phase was then cleaved with conc. aqueous $\mathrm{NH}_{3}$ at $25^{\circ} \mathrm{C}$ for $17 \mathrm{~h}$, purified by HPLC and concentrated. The removal of the MMTr protection group on the hydroxylamine was carried out by dissolving the obtained oligonucleotide in acetic acid aq. (20\%, $200 \mu \mathrm{L})$ at $25{ }^{\circ} \mathrm{C}$ for $30 \mathrm{~min}$, precipitated by addition of sodium acetate solution $(3 \mathrm{M}, 60 \mu \mathrm{L})$ and $\mathrm{EtOH}(1040 \mu \mathrm{L})$, and then purified again with HPLC. 


\section{Schiff base formation between fdC-oligonucleotides and probe strands}

A mixture of $\mathrm{fdC}$ containing oligonucleotides $(\mathbf{T 1}, \mathbf{2})$, or $\mathrm{T} / \mathrm{C} / \mathrm{mC} / \mathrm{hmC} / \mathrm{caC} / \mathrm{Abasic}$ containing oligonucleotides (T3-8) in control experiments $(15 \mu \mathrm{M}, 20 \mu \mathrm{L}, 0.3 \mathrm{nmol}, 1$ eq.), probe strands ( $15 \mu \mathrm{M}, 20 \mu \mathrm{L}, 0.3$ nmol, 1 eq.), $\mathrm{NaCl}$ aq. (1 M, $15 \mu \mathrm{L}), \mathrm{NaOAc}$ aq. $(\mathrm{pH}=6.0,100 \mathrm{mM}, 15 \mu \mathrm{L})$ and $\mathrm{ddH}_{2} \mathrm{O}(80 \mu \mathrm{L})$ was prepared to make a final volume of $150 \mu \mathrm{L}$ (oligonucleotide working concentration $2 \mu \mathrm{M}$ ). The mixture was heated to $85{ }^{\circ} \mathrm{C}$ for $5 \mathrm{~min}$ then slowly cooled down to $25^{\circ} \mathrm{C}$ in $3 \mathrm{~h}$. A first aliquot $(15$ $\mu \mathrm{L})$ was taken and quenched before $5.4 \mu \mathrm{L}$ of 4-methoxyaniline solution $(250 \mathrm{mM}$, $\mathrm{ddH}_{2} \mathrm{O} / \mathrm{DMSO}, \mathrm{v} / \mathrm{v} 9 / 1$, acidified to $\mathrm{pH}=5.5$ with acetate acid) was added to give a catalyst working concentration of $10 \mathrm{mM}$. The reaction was conducted at $25{ }^{\circ} \mathrm{C}, 500$ rpm for $24 \mathrm{~h}$. Aliquots $(15 \mu \mathrm{L})$ were taken at 1, 2, 4, 6, 8, 12, $24 \mathrm{~h}$ and quenched by addition of loading buffer. All the samples were heated at $85^{\circ} \mathrm{C}$ for 3 min followed by PAGE assay as mentioned above.

When using 1,4-benzenediamine as the catalyst, a $10 \mathrm{mM}$ stock solution of $10 \mathrm{mM}$ in $0.5 \%$ acetic acid aq. was prepared.

\section{Melting point experiments}

Melting profiles were measured on a JASCO V-650 spectrometer using quartz glass cuvettes with $10 \mathrm{~mm}$ path length. The samples contained $100 \mathrm{mM} \mathrm{NaCl}, 10 \mathrm{mM}$ NaOAc buffer pH 6.0 and $1 \mu \mathrm{M}$ of each strand in a final volume of $200 \mu \mathrm{L}$. The measurement was repeated three times with independent sample. Before the measurement, the oligonucleotides were hybridized by slowly cooling down the samples from $85^{\circ} \mathrm{C}$ to room temperature. The solutions were covered with silicon oil and tightly plugged. Absorbance was recorded in the forward and reverse direction at temperatures from $25{ }^{\circ} \mathrm{C}$ (or $15{ }^{\circ} \mathrm{C}$ ) to $85^{\circ} \mathrm{C}$ with a slope of $1{ }^{\circ} \mathrm{C} / \mathrm{min}$. $\mathrm{T}_{\mathrm{M}}$ values were calculated as the zero-crossing of $2^{\text {nd }}$ derivate of the $339 \mathrm{~nm}$ background corrected change in hyperchromicity at $260 \mathrm{~nm}$. 
Table S1. Synthesized oligonucleotides in this study. (Letters in bold and italic stand for 2'-O-propargyl nucleosides or epigenetic modifications.)

\begin{tabular}{cllcc}
\hline Entry & Description & 5'----------3' & Calc. & Exptl. \\
\hline T1 & ODN-fC & GTAATGfCGCTAGG & 4040.9 & 4036.2 \\
T2 & fC-shift & GTAATfCCGCTAGG & 4000.9 & 3999.6 \\
T3 & fC-T & GTAATGTGCTAGG & 4027.7 & 4024.7 \\
T4 & fC-C & GTAATGCGCTAGG & 4012.7 & 4008.6 \\
T5 & fC-mC & GTAATGmCGCTAGG & 4026.7 & 4021.6 \\
T6 & fC-hmC & GTAATGhmCGCTAGG & 4042.7 & 4039.6 \\
T7 & fC-caC & GTAATGcaCGCTAGG & 4056.7 & 4054.9 \\
T8 & fC-Abasic & GTAATGAPGCTAGG & 3919.6 & 3916.4 \\
\hline & Probe-1-alkyne & CCUAGCGCATTAC & 3932.7 & 3930.5 \\
P1 & Probe-1-MMTr & CCUAGCGCATTAC & 4335.2 & 4335.1 \\
& Probe-1-ONH2 & CCU*AGCGCATTAC & $4084.8^{[a]}$ & 4084.2 \\
& Probe-2-MMTr & CCUATCGCATTAC & 4310.2 & 4310.3 \\
P2 & Probe-2-ONH 2 & CCU*ATCGCATTAC & $4059.8^{[a]}$ & 4064.3 \\
\hline
\end{tabular}

[a] contains one sodium ion 

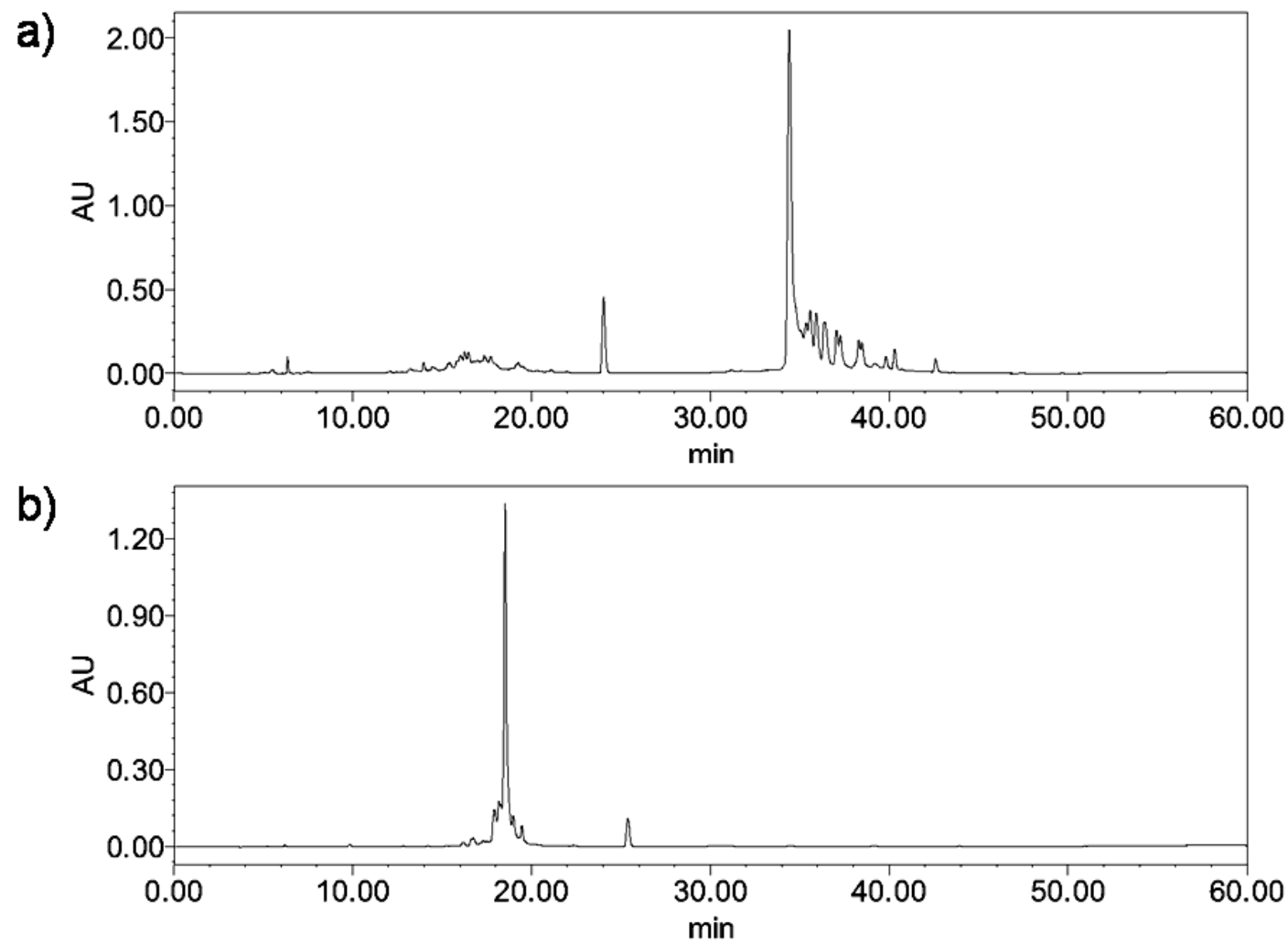

Figure S1. Typical HPLC trace of crude product a) P1-MMTr and b) P1-ONH2. Conditions: buffer A, 0.1 M TEAA; buffer B, 0.1 M TEAA in $80 \%$ acetonitrile, linear gradient from $0 \%$ to $60 \%$ B over $45 \mathrm{~min}$. Retation time: (a) $34.4 \mathrm{~min}$, (b) $18.5 \mathrm{~min}$. $\mathrm{AU}=$ arbitrary unit. 


\section{Crosslinking studies with the synthesized strands}
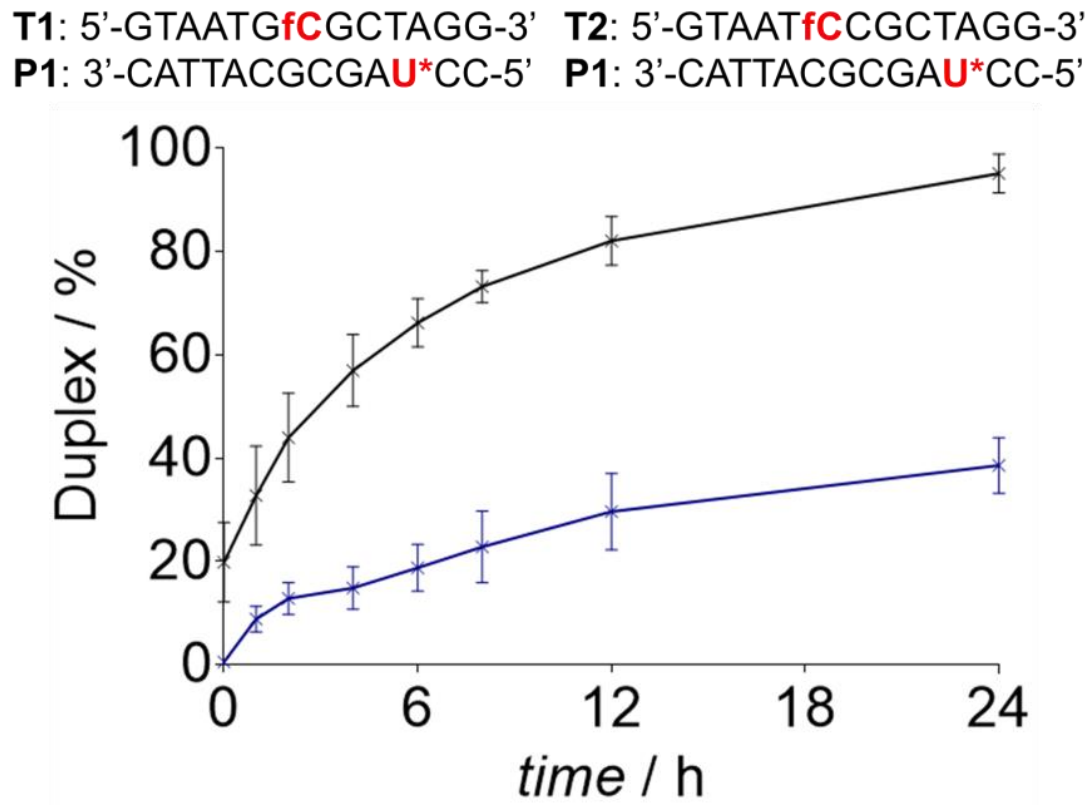

Figure S2. Quantification of the DNA duplex formation during the reaction using the catalyst 4-methoxyaniline. Black line: duplex formation between T1 and P1, blue line: duplex formation between T2 and P1. Error bars represent the standard error of the mean calculated from three replicates.

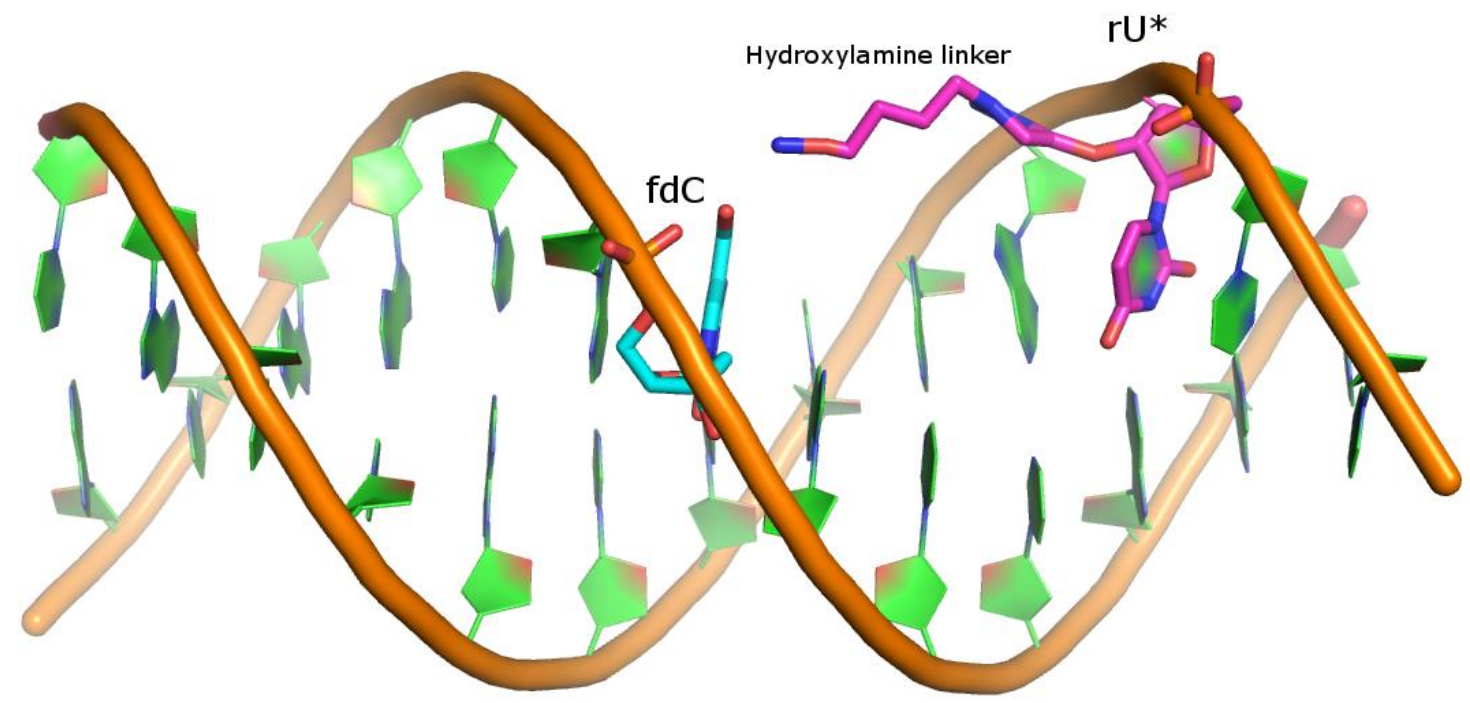

Figure S3. Model representation of a duplex showing the position of the hydroxylamine linker relative to the $\mathrm{fdC}$ on the complementary strand. 

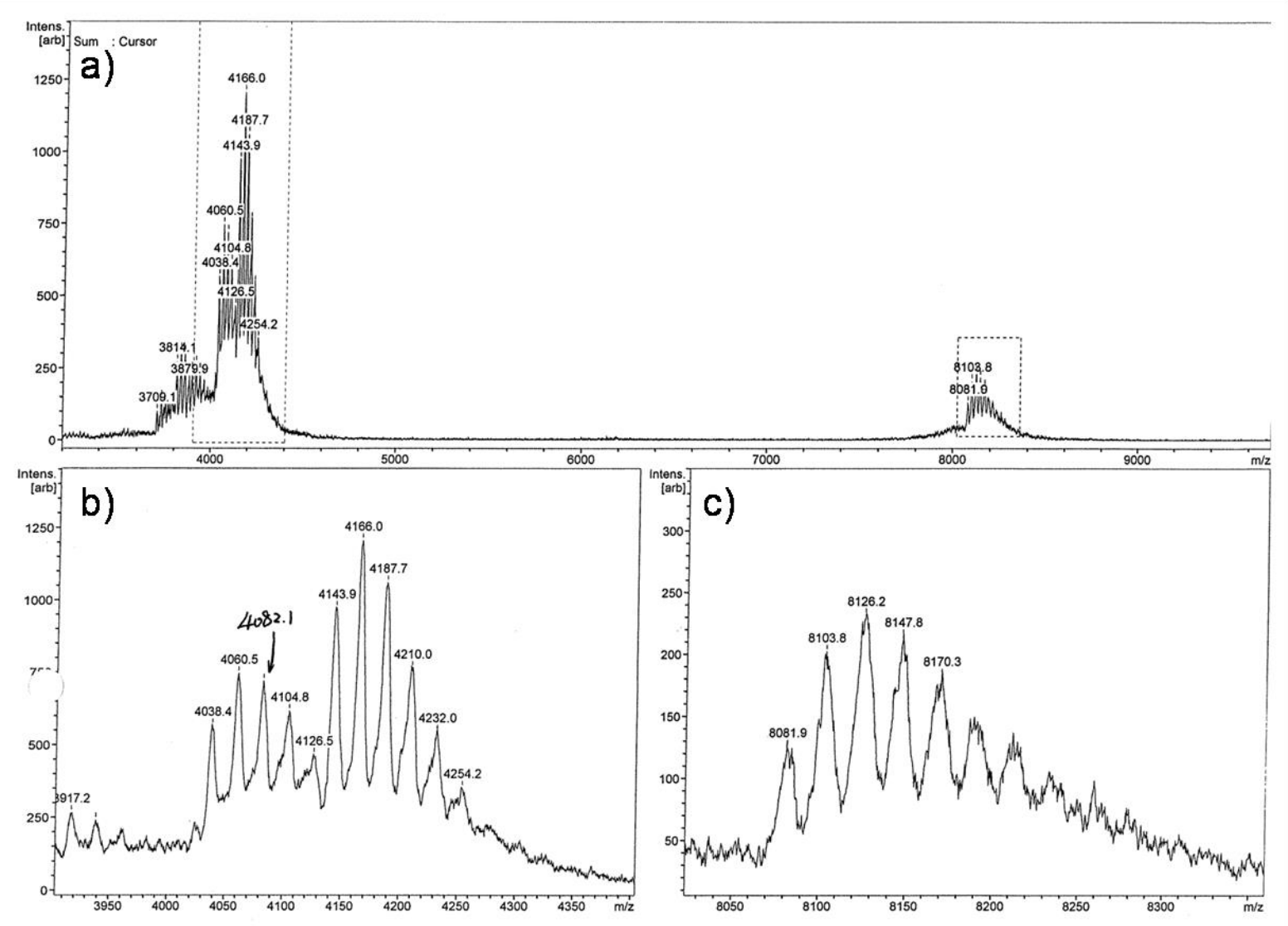

\begin{tabular}{cccc}
\hline No. & 5'-----------3' & Calc. & Exptl. \\
\hline P1 & CCU*AGCGCATTAC & 4061.8 & 4060.5 \\
T1 & GTAATGfCGCTAGG & 4040.9 & 4038.4 \\
T1 & GTAATGfCGCTAGG & $4146.0^{[a]}$ & 4143.9 \\
T1:P1 & & 8084.7 & 8081.9 \\
\hline
\end{tabular}

[a] conjugate with 4-methoxyaniline

Figure S4. MALDI-TOF mass spectrum of the crosslinked duplex T1:P1 and single strands. a) Overall MALDI-TOF spectrum; b) peaks corresponding to single strands P1 and P1- 4-methoxyaniline conjugate; c) peaks corresponding to linked duplex T1:P1. Conditions: $10 \mu \mathrm{M}$ oligonucleotides, $100 \mathrm{mM} \mathrm{NaCl}, 10 \mathrm{mM} \mathrm{NaOAc}$ buffer $\mathrm{pH} 6.0$. 


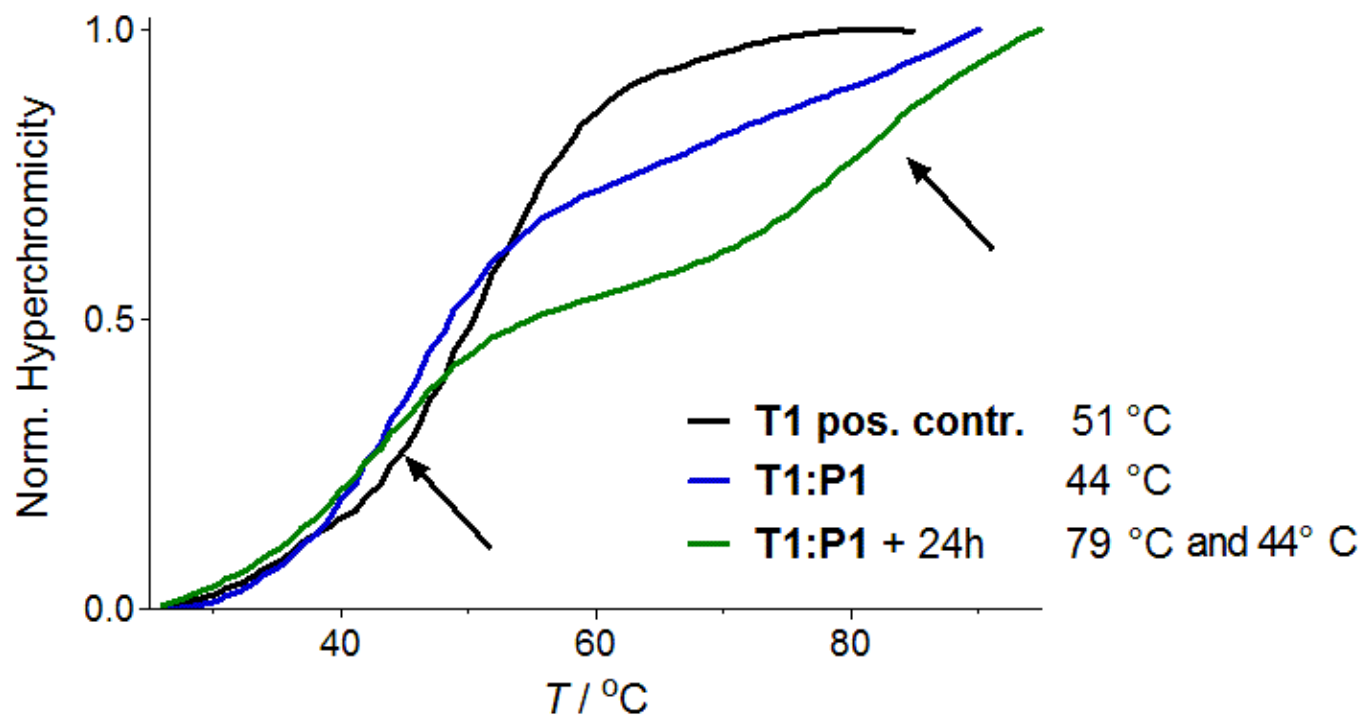

Figure S5. Melting curves of duplex T1:P1 after reannealing or after $24 \mathrm{~h}$ incubation without catalyst compared with duplex $\mathbf{T 1}$ and its counter strand (positive control). Conditions: $1 \mu \mathrm{M}$ oligonucleotides, $100 \mathrm{mM} \mathrm{NaCl}, 10 \mathrm{mM}$ NaOAc buffer $\mathrm{pH}$ 6.0, the final volume of $200 \mu \mathrm{L}$. 


\section{Experimental details of the genomic fdC profiling study}

\section{Cell culture and genomic DNA isolation}

J1 wild type stem cells (strain 129/SvJae), ${ }^{[1]}$ Dnmt TKO (J1, strain 129/SvJae), ${ }^{[2]}$ $\mathrm{Tdg}^{+-}$(E14, strain 129/Ola) and the $\mathrm{Tdg}^{-/-}$cell line (E14, strain 129/Ola), ${ }^{[3]}$ were routinely maintained on gelatinized plates in DMEM (Sigma-Aldrich) supplemented with 10\% FBS (PAN Biotech), 1x MEM-nonessential amino acids (NEAA), $0.2 \mathrm{mM}$ L-alanyl-L-glutamine, 1x penicillin-streptomycin, $0.1 \mathrm{mM} ß$-mercaptoethanol (all from Sigma-Aldrich), $1000 \mathrm{U} / \mathrm{ml}$ mouse recombinant LIF (ORF Genetics), $1 \mu \mathrm{M}$ PD 0325901 and $3 \mu \mathrm{M}$ CHIR 99021 (2i; both from Axon Medchem). In these conditions, global genomic $\mathrm{mC}$ levels are very low and its oxidized derivatives are even lower, as we described previously. ${ }^{[4]}$ For the experiments, the cultures were passaged twice (over five days), in DMEM supplemented with FBS and LIF, but lacking 2i. With this strategy, primed mESC cultures were obtained and oxidized cytosine derivatives reached reproducibly higher and stable levels. ${ }^{[4]}$ In case of the experiment using J1 wild type and Dnmt TKO cells, the cultures were passaged every second day over a period of six days.

Mouse embryonic stem cells were lysed directly in the plates with RLT-buffer (Qiagen). The lysates were homogenized with a TissueLyser MM400 (Retsch) for $1 \mathrm{~min}$ at $30 \mathrm{~Hz}$ and centrifuged for $5 \mathrm{~min}$ at $21000 \mathrm{xg}$. Then genomic DNA was isolated using the Zymo Quick gDNA Midi Kit according to the manufacturer's instruction. The concentration was measured using a Nanodrop ND-1000 (Peqlab).

\section{Probe crosslinking}

The gDNA solution obtained above $(1.2 \mu \mathrm{g})$, the fdC probe $(\mathbf{P})(1 \mu \mathrm{M}, 2 \mu \mathrm{L})$, $\mathrm{NaH}_{2} \mathrm{PO}_{4}-\mathrm{Na}_{2} \mathrm{HPO}_{4}$ buffer $(200 \mathrm{mM}, \mathrm{pH}=6.0,2 \mu \mathrm{L}), \mathrm{NaCl}$ aq. $(1.5 \mathrm{M}, 2 \mu \mathrm{L})$, and $\mathrm{ddH}_{2} \mathrm{O}$ were mixed to a final volume of $18 \mu \mathrm{L}$. The mixture was heated to $95{ }^{\circ} \mathrm{C}$ for 3 min, and then cooled down rapidly to $25^{\circ} \mathrm{C}$. 1,4-Benzenediamine aq. (10 mM, $\left.2 \mu \mathrm{L}\right)$ was added and the reaction vial shaken $(300 \mathrm{rpm})$ for $6 \mathrm{~h}$ at $25^{\circ} \mathrm{C}$. First, the mixture was neutralized with $\mathrm{Na}_{2} \mathrm{HPO}_{4}$ aq. $(200 \mathrm{mM}, 40 \mu \mathrm{L})$, and then purification with $N E B$ Monarch PCR DNA Cleanup Kit using the binding buffer $(120 \mu \mathrm{L})$ and eluting with the elution buffer (Tris-EDTA) $(30 \mu \mathrm{L})$. The eluted solution was quantified with the Nanodrop and 22-32 $\mathrm{ng} / \mu \mathrm{L}$ was obtained. UV spectra confirmed the main peak centered at $260 \mathrm{~nm}$. 


\section{Ligation}

The crosslinked gDNA solution (300 ng), reporter strand $(\mathbf{R})(20 \mathrm{nM}, 1 \mu \mathrm{L})$, Ampligase reaction buffer $(10 \times, 2 \mu \mathrm{L})$, Ampligase from Epicenter $(5 \mathrm{U} / \mu \mathrm{L}, 2 \mu \mathrm{L}, 10$ $\mathrm{U})$ and $\mathrm{ddH}_{2} \mathrm{O}$ were mixed to a final volume of $20 \mu \mathrm{L}$. The mixture was heated to $95{ }^{\circ} \mathrm{C}$ for $3 \mathrm{~min}$, and then to $94{ }^{\circ} \mathrm{C}$ for $1 \mathrm{~min}, 60{ }^{\circ} \mathrm{C}$ for $1 \mathrm{~h}$ and back to $94{ }^{\circ} \mathrm{C}$ for 10 cycles. Then, the reaction mixture was diluted with Tris- $\mathrm{HCl}$ buffer $(200 \mathrm{mM}, \mathrm{pH}=$ 7.6, $50 \mu \mathrm{L}$ ) before purification with NEB Monarch PCR DNA Cleanup Kit using the binding buffer $(140 \mu \mathrm{L})$ and eluting with the elution buffer $(10 \mu \mathrm{L})$. The eluted solution was quantified with the Nanodrop, obtaining 20-32 ng/ $\mu \mathrm{L}$. UV spectra confirmed the main peak centered at $260 \mathrm{~nm}$.

\section{Droplet digital PCR}

ddPCR experiments were performed on a Bio-Rad QX100 ddPCR System. For one reaction, gDNA (6 ng), four primers $(18 \mu \mathrm{M}$ each, $1 \mu \mathrm{L})$, two TaqMan probes $(5 \mu \mathrm{M}$ each, $1 \mu \mathrm{L}$ ), digital PCR Supermix for Probes (no dUTP, $2 \times, 10 \mu \mathrm{L}$ ), and $\mathrm{ddH}_{2} \mathrm{O}$ were mixed to a final volume of $20 \mu \mathrm{L}$ with primer working concentration of $900 \mathrm{nM}$ and TaqMan probe working concentration of $250 \mathrm{nM}$.

PCR cycles were conducted on a Bio-Rad T100 Thermal cycler. PCR cycle: $95^{\circ} \mathrm{C}$ for $10 \mathrm{~min}, 94^{\circ} \mathrm{C}$ for $30 \mathrm{sec}$ and specific annealing temperature $\left(64^{\circ} \mathrm{C}\right)$ for $1 \mathrm{~min}$ for 35 or 40 cycles, then $98^{\circ} \mathrm{C}$ for $10 \mathrm{~min}$ and cooled down to $12^{\circ} \mathrm{C}$. A temperature ramp of $2{ }^{\circ} \mathrm{C} / \mathrm{s}$ was used. Droplet generation and counting were conducted according to the manufacturer's instructions, i.e. reaction mixture prepared as above $(20 \mu \mathrm{L})$ and ddPCR droplet generate oil $(70 \mu \mathrm{L})$ were used per reaction. The accounted droplet number was retained in 10000-18000. FAM for detection amplicon was set to channel 1; HEX for reference amplicon was set to channel 2.

Each percentage value represents the averages and standard deviations from the mean of at least two technical replicates and two biological replicates. LC-MS quantification were conducted according to the previous report. ${ }^{[5]}$

\section{References}

[1] E. Li, T. H. Bestor, R. Jaenisch, Cell 1992, 69, 915-926.

[2] A. Tsumura, T. Hayakawa, Y. Kumaki, S. Takebayashi, M. Sakaue, C. Matsuoka, K. Shimotohno, F. Ishikawa, E. Li, H. R. Ueda, J. Nakayama, M. Okano, Genes Cells 2006, $11,805-814$.

[3] D. Cortazar, C. Kunz, J. Selfridge, T. Lettieri, Y. Saito, E. MacDougall, A. Wirz, D. Schuermann, A. L. Jacobs, F. Siegrist, R. Steinacher, J. Jiricny, A. Bird, P. Schar, Nature 2011, 470, 419-423. 
[4] T. Pfaffeneder, F. Spada, M. Wagner, C. Brandmayr, S. K. Laube, D. Eisen, M. Truss, J. Steinbacher, B. Hackner, O. Kotljarova, D. Schuermann, S. Michalakis, O. Kosmatchev, S. Schiesser, B. Steigenberger, N. Raddaoui, G. Kashiwazaki, U. Muller, C. G. Spruijt, M. Vermeulen, H. Leonhardt, P. Schar, M. Muller, T. Carell, Nat Chem Biol 2014, 10, 574-581.

[5] M. Wagner, J. Steinbacher, T. F. J. Kraus, S. Michalakis, B. Hackner, T. Pfaffeneder, A. Perera, M. Müller, A. Giese, H. A. Kretzschmar, T. Carell, Angew. Chem., Int. Ed. 2015, $54,12511-12514$.

a)

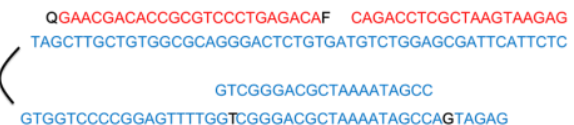
GTCGTGGTCATCTCC 法 ССTCCGACCTGAGTTCGTGATTTTGATCCTCGGTCGGTCCCCGGAG GGCTGGACTCAAGCAACTAA TTAGCCAGTAGAGGTTIGATTTGGCH TAGACTCCTGTCTCCACACA

b)

\begin{tabular}{|c|c|c|c|}
\hline Entry & Description & $5^{\prime}$ & mer \\
\hline P2 & probe for locus 1 & GAGATG*ACCGATAAAATCGCAGGGC & 25 \\
\hline R1 & report strand for locus 1 & $\begin{array}{l}\text { pTGGTITGAGGCCCCTGGTGTAGCTTGCTGTGGCG } \\
\text { CAGGGACTCTGTGATGTCTGGAGCGATTCATTCTC }\end{array}$ & 70 \\
\hline \multirow{6}{*}{ locus 1} & detection forward primer & CCGATAAAATCGCAGGGCTG & 20 \\
\hline & detection reverse primer & GAGAATGAATCGCTCCAGAC & 20 \\
\hline & detection TaqMan probe & F-ACAGAGTCCCTGCGCCACAGCAAG-Q & 24 \\
\hline & reference forward primer & GGCTGGACTCAAGCAACTAA & 20 \\
\hline & reference reverse primer & ACACACCTCTGTCCTCAGAT & 20 \\
\hline & reference TaqMan probe & H-CGGTITAGTITGGAGATGACCGAT-Q & 24 \\
\hline P3 & probe for locus 2 & 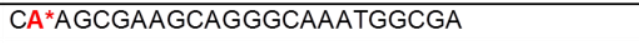 & 24 \\
\hline R2 & report strand for locus 2 & $\begin{array}{l}\text { pTCTCGAACCTCTGCCAGCCTAGCTTGCTGTGGCGC } \\
\text { AGGGACTCTGTGATGTCTGGAGCGATTCATTCTC }\end{array}$ & 69 \\
\hline \multirow{6}{*}{ locus 2} & detection forward primer & AAGCAGGGCAAATGGCGA & 19 \\
\hline & detection reverse primer & GAGAATGAATCGCTCCAGAC & 20 \\
\hline & detection TaqMan probe & F-ACAGAGTCCCTGCGCCACAGCAAG-Q & 24 \\
\hline & reference forward primer & CCAGGGAGCATCTGTGAAAA & 20 \\
\hline & reference reverse primer & AAAAGCCCATCTGGGAAACA & 20 \\
\hline & reference TaqMan probe & H-CCCCTTCAGACGCAAGCGAAGCAG-Q & 24 \\
\hline
\end{tabular}

Figure S6. Sequence detail of the detection strategy: a) Illustration of the detection strategy with sequence details for locus 1 , i.e. $30,020,539^{\text {th }}$ position on chromosome 16 (MM9); b) synthesized and purchased oligonucleotides for locus 1 and 2. Bold and red letters represent nucleoside modifications or functional group: $\mathrm{p}$, phosphate group at 5' terminus; F, FAM; H, HEX; Q, BHQ-1. MALDI-TOF: P2: calc.7951.5, found 7948.5, P3 calc. 7672.5, found 7671.0, contain one sodium ion. 


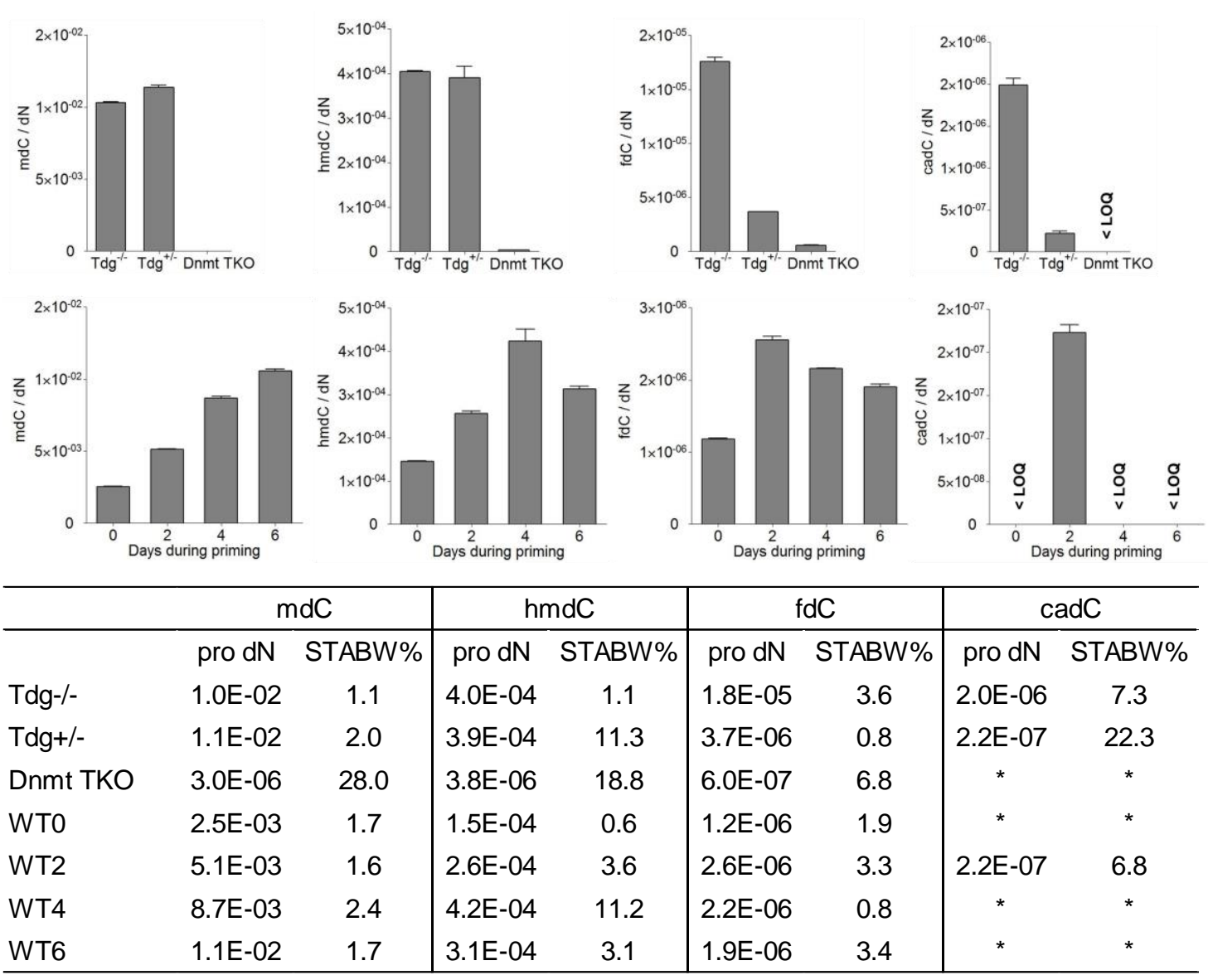

Figure S7. Global $5 \mathrm{mC}, 5 \mathrm{hmC}$, fdC, and $5 \mathrm{caC}$ quantification using LC-MS: $\mathrm{Tdg}^{-/-}$, $\mathrm{Tdg}^{+-}$, and Dnmt TKO mES cells and 0, 2, 4, 6 days during priming of wild-type mES cells. *: $<\mathrm{LOQ}$, below the limit of quantification. 
a)

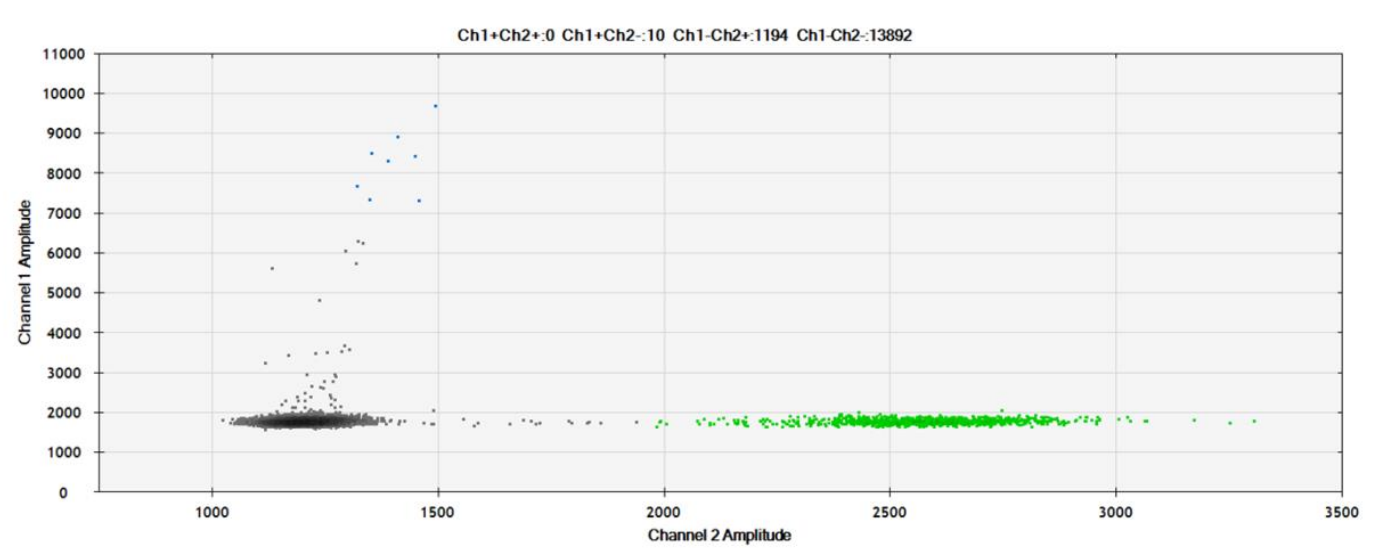

b)

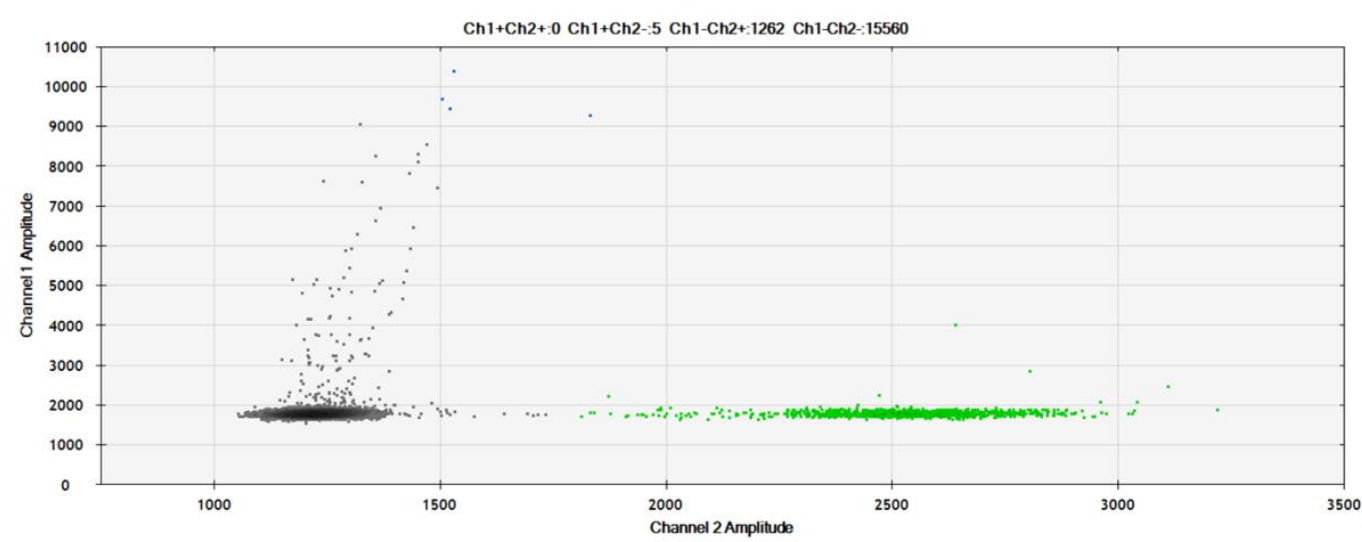

c)

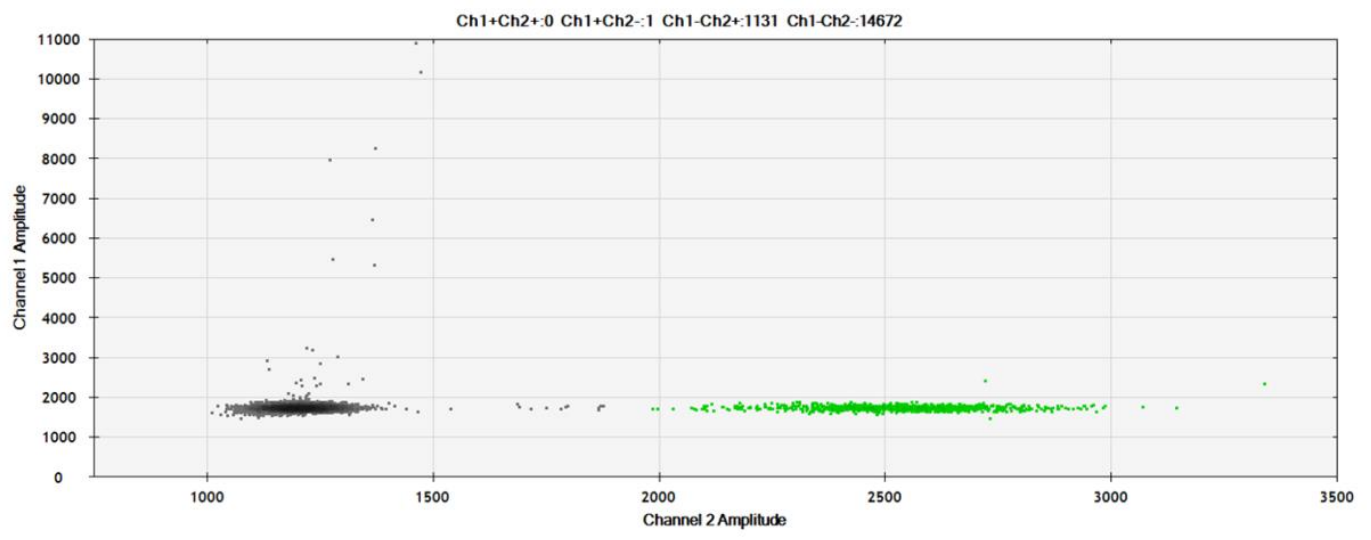

Figure S8. 2-D plot of droplet fluorescence for negative control of locus 1: a) P3, instead of P2, was used; b) no reporter stand $\mathbf{R 1}$; c) no Ampligase. 


\section{Quantification modeling}

The encapsulation maximum of one target amplicon in one droplet to generate a positive or negative signal is the ideal scenario for our situation. If a droplet contains more than one detection amplicon, for example, one contains one fdC and one cytosine, it will show a positive signal, and the negative cytosine signal vanishes.

The probability for two or more detection amplicons to get into one droplet can be calculated according to the Poisson distribution, i.e. a discrete random variable $\mathrm{X}$ complies the Poisson distribution with parameter $\lambda>0$, if, for $\mathrm{k}=0,1,2, \ldots$, the probability mass function of $\mathrm{X}$ is given by:

$$
f(k ; \lambda)=\operatorname{Pr}(\mathrm{X}=k)=\frac{\lambda^{k} e^{-\lambda}}{k !}
$$

where e is Euler's number and $k$ ! is the factorial of $k$.

Table S2 Poisson distribution probabilities of genome copies in the droplet.

\begin{tabular}{lllllll}
\hline \multirow{2}{*}{$\begin{array}{l}\text { input } \\
\mathrm{ng}\end{array}$} & \multirow{2}{*}{$\lambda$} & \multicolumn{5}{c}{$k$} \\
\cline { 3 - 7 } 3 & 0.05 & $4.8 \%$ & $0.1 \%$ & $0.0 \%$ & $0.0 \%$ & $0.0 \%$ \\
6 & 0.10 & $9.0 \%$ & $0.5 \%$ & $0.0 \%$ & $0.0 \%$ & $0.0 \%$ \\
9 & 0.15 & $12.9 \%$ & $1.0 \%$ & $0.0 \%$ & $0.0 \%$ & $0.0 \%$ \\
10 & 0.17 & $14.1 \%$ & $1.2 \%$ & $0.1 \%$ & $0.0 \%$ & $0.0 \%$ \\
15 & 0.25 & $19.5 \%$ & $2.4 \%$ & $0.2 \%$ & $0.0 \%$ & $0.0 \%$ \\
20 & 0.33 & $23.9 \%$ & $4.0 \%$ & $0.4 \%$ & $0.0 \%$ & $0.0 \%$ \\
30 & 0.50 & $30.3 \%$ & $7.6 \%$ & $1.3 \%$ & $0.2 \%$ & $0.0 \%$ \\
40 & 0.67 & $34.2 \%$ & $11.4 \%$ & $2.5 \%$ & $0.4 \%$ & $0.1 \%$ \\
\hline
\end{tabular}

For example, the mass of a mouse genome is approximately $3.0 \mathrm{pg}\left(3.0 \times 10^{-12} \mathrm{~g}\right)$. If 30 ng for a $20 \mu \mathrm{L}$ reaction is used, 10,000 genomes will be distributed into 20,000 droplets. So, $\lambda$ equals to $10,000 / 20,000=0.50$. Let $\mathrm{X}=1$, then $f(1 ; 0.50)=0.303$; let $\mathrm{X}=2$, then $f(2 ; 0.50)=0.076$. This means $30.3 \%$ of the droplets, instead $50 \%$ of the droplet, contain a single copy while $7.6 \%$ of the droplets contain two copies. Extensive distribution probabilities are listed in Table S2. If less than $9 \mathrm{ng}$ is settled in a $20 \mu \mathrm{L}$ reaction, the probability to have two copies inside one droplet will be lower than $1 \%$. For the ease of calculation, $6 \mathrm{ng}$ gDNA is used for each reaction of $20 \mu \mathrm{L}$, corresponding to ca. $90 \mathrm{copy} / \mu \mathrm{L}$. 
a)

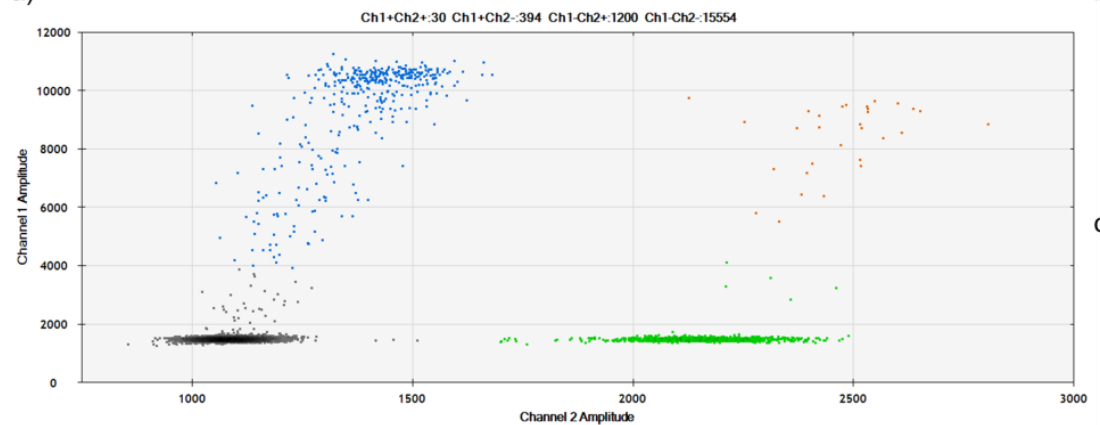

b)

\begin{tabular}{c|c} 
Ch1 + & Ch1 + \\
Ch2 - & Ch2+ \\
\hline Ch1 - & Ch1- \\
Ch2- & Ch2 +
\end{tabular}

c)

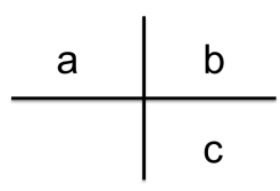

Figure S9. ddPCR output and modeling: a) 2-D plot of droplet fluorescence for illustration; b) clusters separation in four quadrants; c) algebraic simplification of counting numbers of the clusters.

As shown in Figure $\mathrm{S} 8, \mathrm{Ch} 1+\mathrm{Ch} 2+$ (yellow) refers to droplets with both positive signals; Ch1+Ch2- (blue) refers to droplets with only detection (report strand) signal; Ch1-Ch2+ (green) refers to droplets with only reference (gDNA) signal; Ch1-Ch2(black) refers to droplets without target locus and ligated product; AD refers to all the droplets accepted; resolution refers to the separation of the clusters.

In principle, $\mathrm{Ch} 1+\mathrm{Ch} 2+$ shows the droplets that contain $\mathrm{fdC}$ sites in the target locus; Ch1+Ch2- indicates false-positive signals due to unspecific amplification and the dissociated ligated products; Ch1-Ch2+ shows the droplets containing only the target gDNA.

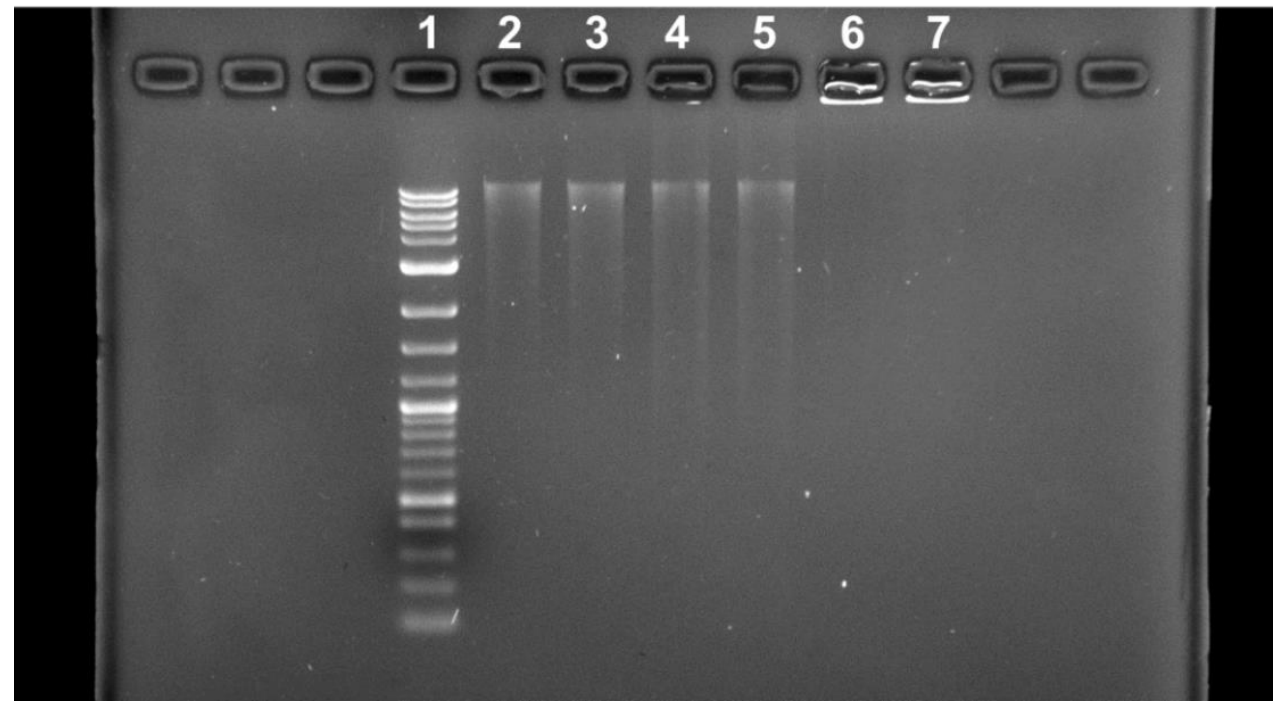

Figure S10. Agarose gel showing gDNA degradation: Line 1, $\log 2$ marker; line 2,3, gDNA (150 ng) after crosslinking; line 4,5, gDNA (150 ng) after ligation cycle, $95^{\circ} \mathrm{C}$ for $3 \mathrm{~min}$, then 10 cycles of $94^{\circ} \mathrm{C}$ for $1 \mathrm{~min}$ and $60^{\circ} \mathrm{C}$ for $1 \mathrm{~h}$; line 6,7 , gDNA (150 ng). 
Without considering the dissociation of the ligated products, the unreacted probe which remained in the system will cause unspecific amplification, i.e. $\mathrm{Ch} 1+\mathrm{Ch} 2-$ signals. Catalyst, acid buffer, and ligation cycles will cause gDNA degradation (Figure S9, giving more $\mathrm{Ch} 1+\mathrm{Ch} 2-$ false-negative signals. However, $\mathrm{Ch} 1+\mathrm{Ch} 2-$ and Ch1+Ch2- / Ch1-Ch2- resolution do not play a role in the mathematical modelling that we used.

Assuming that all $\mathrm{fdC}$ at the target site is converted to the reporter strand via crosslinking and ligation, the yield is $100 \%$. Assume that there are less than 150 copies in $1 \mu \mathrm{L}$ so that the Poisson distribution is exclusive in our model.

Let $\mathrm{a}=\mathrm{Ch} 1+\mathrm{Ch} 2-, \mathrm{b}=\mathrm{Ch} 1+\mathrm{Ch} 2+, \mathrm{c}=\mathrm{Ch} 1-\mathrm{Ch} 2+,($ Figure S8) A = Accepted droplet for the experiment entry, respectively, a', b', c', and $A^{\prime}$ for the control, i.e. TET knockout cell line.

Let $\eta=\mathrm{fdC}$ content of the target site.

Then,

$$
\eta=\frac{\mathrm{a}+\mathrm{b}-\frac{A}{A^{\prime}}\left(a^{\prime}+b^{\prime}\right)}{b+c+\left(a-\frac{A}{A^{\prime}} a^{\prime}\right) / \eta}
$$

where $\mathrm{a}-\frac{\mathrm{A}}{\mathrm{A}^{\prime}} a^{\prime}$ refers to the degraded gDNA copy containing fdC at the target site that does not show in $\mathrm{Ch} 2,\left(\mathrm{a}-\frac{\mathrm{A}}{A^{\prime}} a^{\prime}\right) / \eta$ refers to all the degraded gDNA copies. So,

$$
\eta=\frac{\left(\mathrm{b}-\frac{A}{A^{\prime}} \mathrm{b}^{\prime}\right)}{b+c}
$$

Herein, in this ideal model, without considering the dissociation of the ligated products, $\eta$ is independent of a, a', and c', i.e. genome degradation and unspecific ligation do not affect fdC percentage. Ch1+Ch2- only be resulted from the dissociation of the ligated products. Also, as shown in Figure S6 a-c, b' can be omitted. Simplified $\eta^{\prime}$

$$
\eta^{\prime}=\frac{\mathrm{a}+\mathrm{b}}{b+c}
$$

is calculated to indicate relative abundance of $\mathrm{fdC}$ at the target site.

In reality, neither the fdC probe covers all the target sites nor the reporter strand ligates to all the target-linked probe. Therefore, only relative quantification is possible in our model. 


\section{Droplet digital PCR data}

Raw data of fdC detection in $\mathrm{Tdg}^{-/-}, \mathrm{Tdg}^{+/-}$, Dnmt TKO cells for locus 1. (AD: accepted droplets)

\begin{tabular}{cccccccccc}
\hline & Ch1 & Ch2 & $1+2+$ & $1+2-$ & $1-2+$ & $1-2-$ & AD & $\eta$ & Average \\
\hline Tdg-/- & 17.6 & 67.6 & 151 & 121 & 827 & 16399 & 17502 & $27.8 \%$ & \\
Tdg-/- & 17.6 & 63.7 & 101 & 93 & 590 & 12318 & 14896 & $28.1 \%$ & $28.5 \%$ \\
Tdg-/- & 18.9 & 63.7 & 106 & 103 & 585 & 12308 & 13102 & $30.2 \%$ & \\
Tdg-/- & 28.8 & 103 & 181 & 149 & 1002 & 12743 & 14075 & $27.9 \%$ & \\
\hline Tdg+/- & 11.6 & 74.0 & 54 & 56 & 676 & 11085 & 11878 & $15.1 \%$ & \\
Tdg+/- & 11.3 & 67.2 & 54 & 70 & 698 & 12722 & 13544 & $16.5 \%$ & $15.7 \%$ \\
Tdg+/- & 10.7 & 69.6 & 52 & 83 & 806 & 13994 & 14935 & $15.7 \%$ & \\
Tdg+/- & 10.8 & 72.0 & 56 & 66 & 738 & 12490 & 13350 & $15.4 \%$ & \\
\hline Dnmt TKO & 4.0 & 115.0 & 10 & 29 & 1049 & 10327 & 11415 & $3.7 \%$ & \\
Dnmt TKO & 3.1 & 61.1 & 11 & 17 & 625 & 11913 & 12566 & $4.4 \%$ & \\
Dnmt TKO & 4.1 & 58.0 & 14 & 30 & 620 & 12508 & 13174 & $6.9 \%$ & $5.2 \%$ \\
Dnmt TKO & 2.8 & 60.6 & 8 & 21 & 600 & 11484 & 12119 & $4.8 \%$ & \\
Dnmt TKO & 5.7 & 96.0 & 35 & 28 & 986 & 11998 & 13047 & $6.2 \%$ & \\
\hline
\end{tabular}




\section{Locus $1 \mathrm{Tdg}^{-/-} \mathrm{mES}$ cell sample}
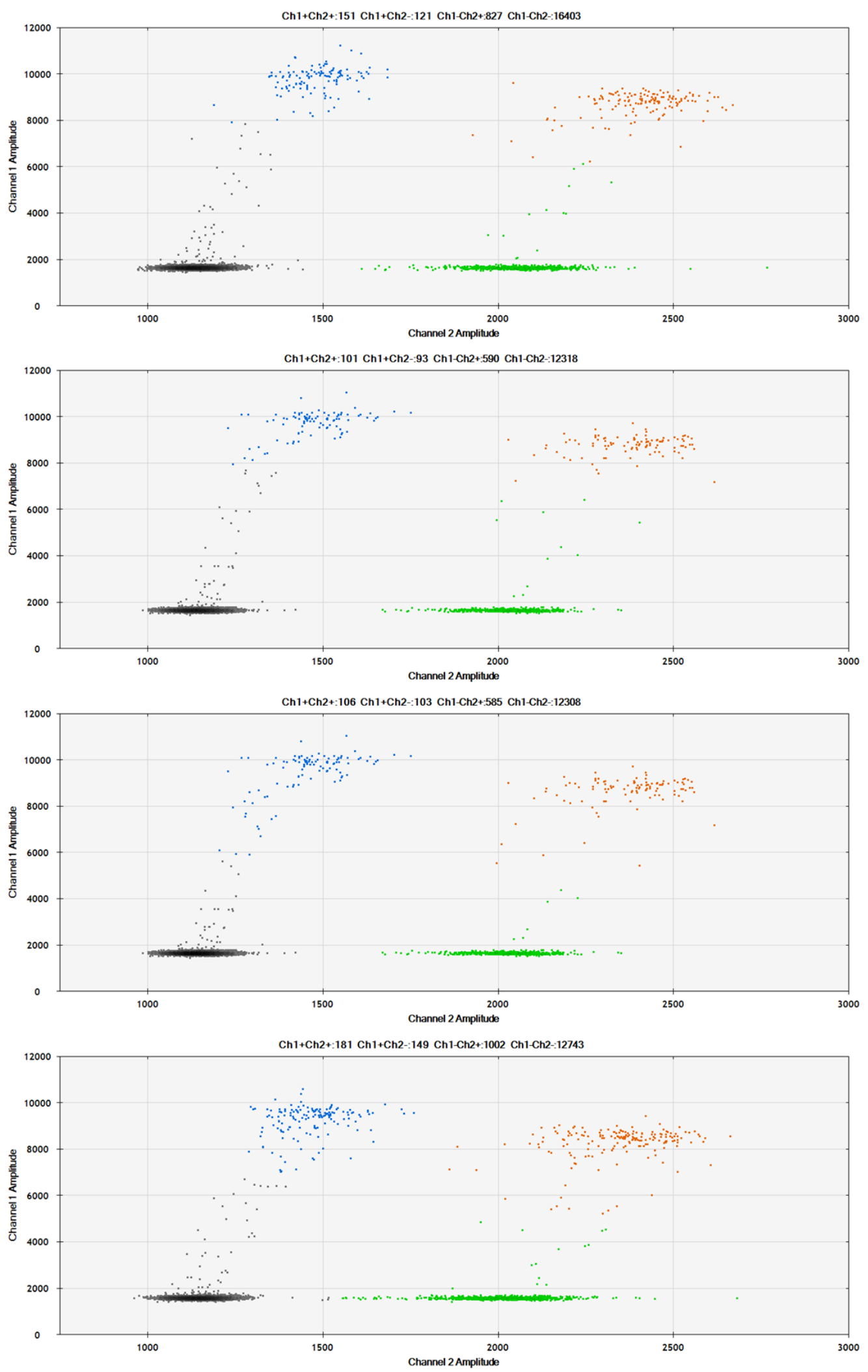


\section{Locus $1 \mathrm{Tdg}^{+/-} \mathrm{mES}$ cell sample.}
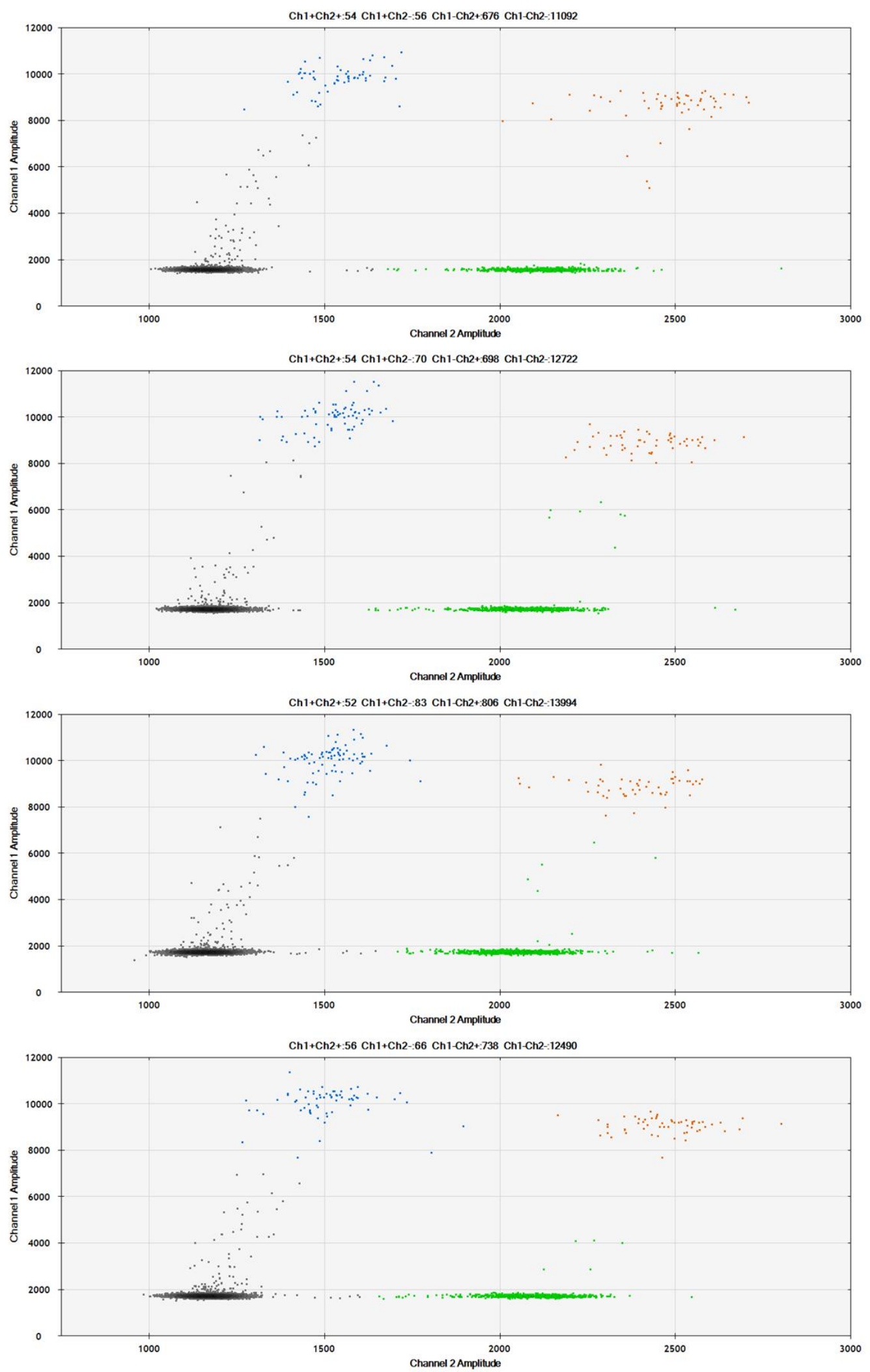
Locus 1 Dnmt TKO mES cell sample.
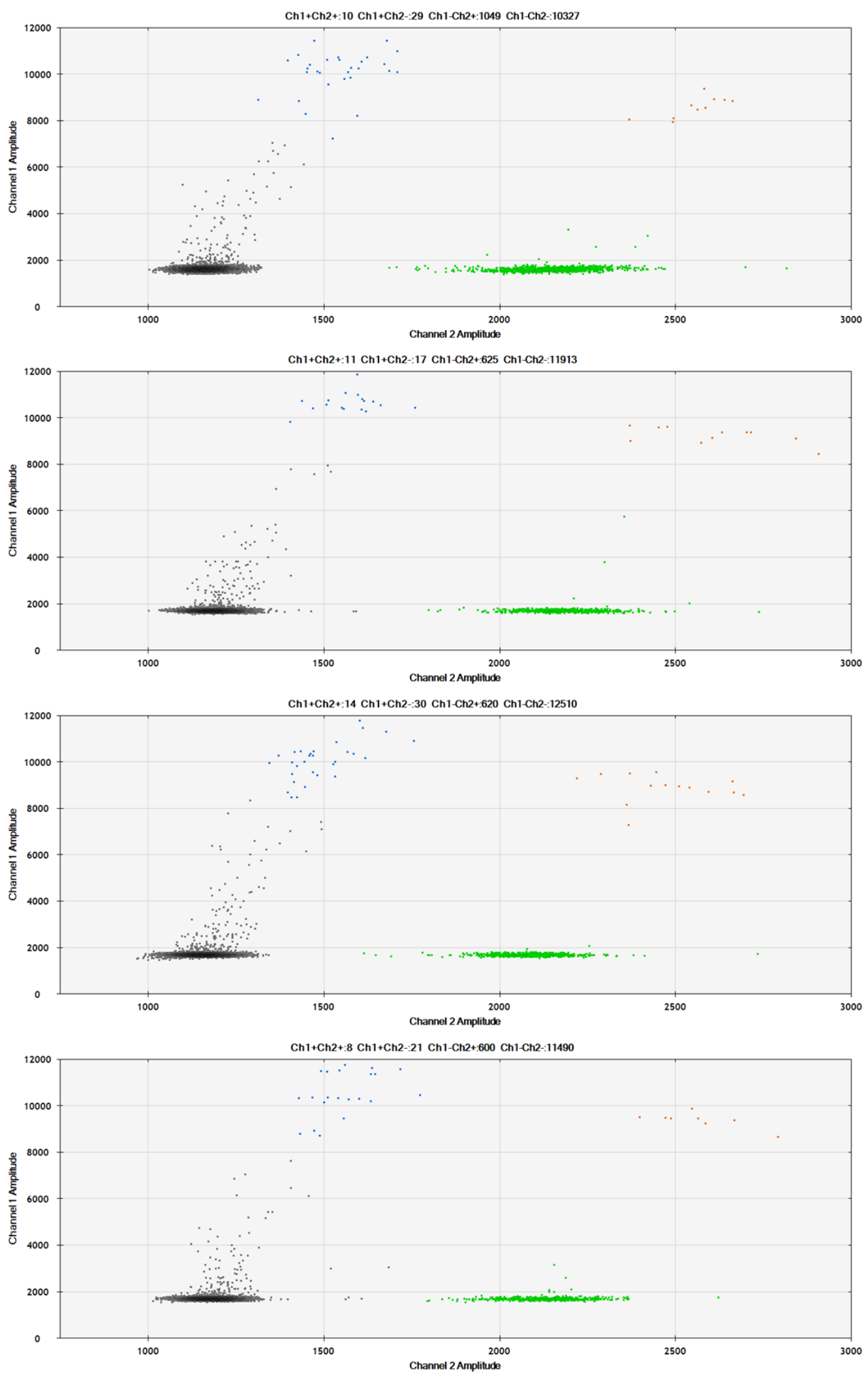
Locus 1 Raw data of fdC detection in wild-type cells during priming.

\begin{tabular}{lccccccccc}
\hline & Ch1 & Ch2 & $1+2+$ & $1+2-$ & $1-2+$ & $1-2-$ & AD & $\eta$ & Average \\
\hline WT0 & 5.4 & 108 & 20 & 34 & 1017 & 10787 & 11858 & $5.21 \%$ & \\
WT0 & 6.8 & 110 & 30 & 58 & 1336 & 13841 & 15265 & $6.44 \%$ & $6.06 \%$ \\
WT0 & 6.6 & 112 & 26 & 53 & 1255 & 12738 & 14072 & $6.17 \%$ & \\
WT0 & 7.8 & 108 & 23 & 58 & 1241 & 13060 & 14382 & $6.41 \%$ & \\
\hline WT2 & 9.7 & 89.2 & 40 & 98 & 1193 & 15552 & 16883 & $11.19 \%$ & \\
WT2 & 10.2 & 88.7 & 35 & 105 & 1249 & 15948 & 17337 & $10.90 \%$ & \\
WT2 & 10.8 & 93.0 & 35 & 96 & 1168 & 14476 & 15771 & $10.89 \%$ & $10.90 \%$ \\
WT2 & 10.2 & 96.0 & 54 & 94 & 1279 & 15637 & 17064 & $11.10 \%$ & \\
WT2 & 6.3 & 56.2 & 19 & 65 & 744 & 15582 & 16410 & $11.01 \%$ & \\
WT2 & 6.0 & 57.3 & 27 & 54 & 759 & 15780 & 16620 & $10.31 \%$ & \\
\hline WT4 & 6.2 & 68.0 & 19 & 30 & 501 & 8702 & 9252 & $9.42 \%$ & \\
WT4 & 5.4 & 68.4 & 26 & 46 & 811 & 13942 & 14821 & $8.60 \%$ & $8.76 \%$ \\
WT4 & 4.5 & 59.0 & 14 & 24 & 477 & 9449 & 9964 & $7.74 \%$ & \\
WT4 & 5.8 & 64.5 & 23 & 43 & 688 & 12579 & 13333 & $9.28 \%$ & \\
\hline WT6 & 11.1 & 117 & 42 & 67 & 1081 & 10691 & 11881 & $9.71 \%$ & \\
WT6 & 8.2 & 114 & 28 & 41 & 888 & 9000 & 9957 & $7.53 \%$ & $8.67 \%$ \\
WT6 & 9.8 & 120 & 32 & 41 & 820 & 7909 & 8802 & $8.57 \%$ & \\
WT6 & 8.5 & 114 & 43 & 57 & 1086 & 11010 & 12196 & $8.86 \%$ & \\
\hline
\end{tabular}

Locus 2 Raw data of fdC detection in $\mathrm{Tdg}^{-/-}, \mathrm{Tdg}^{+/-}$cells

\begin{tabular}{llccccccccc}
\hline Well & & Ch1 & Ch2 & $1+2+$ & $1+2-$ & $1-2+$ & $1-2-$ & AD & $\eta$ & Average \\
\hline H04 & Tdg-/- & 10.5 & 52 & 55 & 92 & 650 & 15671 & 16468 & $20.9 \%$ & \\
E06 & Tdg-/- & 20.8 & 115 & 88 & 133 & 1084 & 11285 & 12590 & $18.9 \%$ & \\
F06 & Tdg-/- & 22.5 & 114 & 98 & 173 & 1226 & 12805 & 14302 & $20.5 \%$ & $19.8 \%$ \\
G06 & Tdg-/- & 20.1 & 109 & 94 & 149 & 1178 & 12927 & 14348 & $19.1 \%$ & \\
H06 & Tdg-/- & 21.8 & 116 & 90 & 159 & 1179 & 12141 & 13569 & $19.6 \%$ & \\
\hline B09 & Tdg+/- & 5.5 & 66 & 28 & 49 & 884 & 15696 & 16657 & $8.4 \%$ & \\
A10 & Tdg+/- & 5.9 & 59 & 13 & 29 & 400 & 8002 & 8444 & $10.2 \%$ & $9.2 \%$ \\
E01 & Tdg+/- & 8.3 & 96 & 43 & 78 & 1299 & 15749 & 17169 & $9.0 \%$ & \\
G01 & Tdg+/- & 8.1 & 93 & 39 & 73 & 1205 & 15070 & 16387 & $9.0 \%$ & \\
\hline
\end{tabular}

